Article

\title{
Enthalpies of Hydrate Formation and Dissociation from Residual Thermodynamics
}

\author{
Solomon Aforkoghene Aromada ${ }^{1, * \mathbb{C}}$, Bjørn Kvamme ${ }^{2}$, Na Wei ${ }^{2}$ and Navid Saeidi ${ }^{3}$ \\ 1 Department of Physics and Technology, University of Bergen, Allegaten 55, 5007 Bergen, Norway \\ 2 State Key Laboratory of Oil and Gas Reservoir Geology and Exploitation, Southwest Petroleum University, \\ Xindu Road No. 8, Chengdu 610500, China; Kvamme_uib@outlook.com (B.K.); weina8081@163.com (N.W.) \\ 3 Environmental Engineering Department, University of California, Irvine, CA 92697, USA; saeidin@uci.edu \\ * Correspondence: Solomon.Aromada@student.uib.no or saromada@gmail.com
}

Received: 18 November 2019; Accepted: 7 December 2019; Published: 11 December 2019

check for updates

\begin{abstract}
We have proposed a consistent thermodynamic scheme for evaluation of enthalpy changes of hydrate phase transitions based on residual thermodynamics. This entails obtaining every hydrate property such as gas hydrate pressure-temperature equilibrium curves, change in free energy which is the thermodynamic driving force in kinetic theories, and of course, enthalpy changes of hydrate dissociation and formation. Enthalpy change of a hydrate phase transition is a vital property of gas hydrate. However, experimental data in literature lacks vital information required for proper understanding and interpretation, and indirect methods of obtaining this important hydrate property based on the Clapeyron and Clausius-Clapeyron equations also have some limitations. The Clausius-Clapeyron approach for example involves oversimplifications that make results obtained from it to be inconsistent and unreliable. We have used our proposed approach to evaluate consistent enthalpy changes of hydrate phase transitions as a function of temperature and pressure, and hydration number for $\mathrm{CH}_{4}$ and $\mathrm{CO}_{2}$. Several results in the literature of enthalpy changes of hydrate dissociation and formation from experiment, and Clapeyron and Clausius-Clapeyron approaches have been studied which show a considerable disagreement. We also present the implication of these enthalpy changes of hydrate phase transitions to environmentally friendly production of energy from naturally existing $\mathrm{CH}_{4}$ hydrate and simultaneously storing $\mathrm{CO}_{2}$ on a long-term basis as $\mathrm{CO}_{2}$ hydrate. We estimated enthalpy changes of hydrate phase transition for $\mathrm{CO}_{2}$ to be $10-11 \mathrm{~kJ} / \mathrm{mol}$ of guest molecule greater than that of $\mathrm{CH}_{4}$ within a temperature range of 273-280 K. Therefore, the exothermic heat liberated when a $\mathrm{CO}_{2}$ hydrate is formed is greater or more than the endothermic heat needed for dissociation of the in-situ methane hydrate.
\end{abstract}

Keywords: hydrate; enthalpy; hydrate formation; residual thermodynamics; $\mathrm{CO}_{2} ;$ methane; hydration number; hydrate dissociation

\section{Introduction}

The international interest in natural gas hydrates as a potential source of energy is increasing rapidly [1-7]. Important global economies [2,5,8] in the world, like for instance Japan and China, are highly dependent on import of energy. These countries have substantial resources of natural gas hydrates [2]. For China, the beneficial situation is that these hydrate energy sources are located offshore as well as onshore in permafrost regions [3,9]. These natural resources have been estimated to be huge in amount by Makogon et al. [2] and Collett [10]. However, the exact or accurate amount is still being debated, thus, uncertain [8]. Klauda and Sandler [11] predicted it is more than 74,200 metric gigatons (Gt) from thermodynamic modelling. While Milkov [12], based on the available information 
on natural gas hydrate distribution puts this amount at $2500 \mathrm{Gt}$. Nevertheless, as stated above, natural gas hydrates are considered as a potential source of unconventional energy for the future [1-8].

A large variety of techniques for mining or production of the energy resources have been recommended in the last three decades till date. Most efforts have been devoted to investigation of thermal stimulation and pressure reduction. A more novel approach of using $\mathrm{CO}_{2}$ is attractive due to the combination of energy production and long-term safe storage of $\mathrm{CO}_{2}$ as hydrate. And as we show in this work the enthalpy changes of hydrate phase transitions of both (methane and carbon dioxide) components will play a vital function in this process. Thus, it is imperative to obtain accurate values of these heat of hydrate formation and dissociation.

However, the data that can be found in literature for enthalpy of hydrate phase transition obtained by experiment most times lack vital information needed for proper understanding and interpretation. Available experimental data for hydrate dissociation enthalpies are filled with various sources of bias that we have discussed in separate papers. Several data available in literature are limited and relevant information needed for proper understanding and interpretation are frequently missing. Sometimes information about pressure, temperature or of both properties is missing [13]. Hydration number and hydrate composition are also not available sometimes. The equation of state applied is also not reported in some literature.

The Clausius-Clapeyron approach is the simplest method that is generally applied to estimate enthalpy change of hydrate phase transition. The calculations are based on hydrate equilibrium data of pressure and temperature from experiments or calculated data. The Clausius-Clapeyron equation is over-simplified, which is the reason for the limitation of the accuracy of estimates especially at higher pressures. Therefore, the ordinary Clapeyron equation is favoured by most recent works applying different models for the change in volume associated with the hydrate phase transitions [14]. The estimates obtained by the use of the Clausius-Clapeyron approach are thus not reliable and not consistent because of its over-simplification. In addition, older data based on Clapeyron equation lack appropriate volume corrections. For example, the work of Anderson [14], hydrate filling fractions even up to $282 \mathrm{~K}$ seem very high. Several experimental data (calorimetry) also lack any measured filling fractions and regularly use a constant value that suggest that they might just be guessed values. Information about superheating above the hydrate equilibrium conditions to completely dissociate the gas hydrate to liquid water and gas is normally not lacking.

However, thermodynamically, enthalpy change is uniquely but trivially related to change in free energy. Therefore, thermodynamic models used for description of change in free energy associated with hydrate phase transition (formation or dissociation) will have a consistent change in enthalpy on the basis of the specific models. This kind of consistent method applies to kinetic theories like classical nucleation theory (CNT) [15], phase-field theory [16-20], and multicomponent diffuse interface theory (MDIT) [21], and other kinetic theory that is complete. Being complete implies there is implicit coupling of heat and mass transports, together with the thermodynamics of phase transition. This is why we propose the use of residual thermodynamics which able to evaluate real and not mere ideal thermodynamic properties and the approach does not have the limitations of the other aforementioned methods. With residual thermodynamics, we can calculate enthalpy changes of hydrate phase transition which are consistent. We can calculate values outside of equilibrium, while the Clausius-Clapeyron and Clapeyron approached are based on equilibrium. Real hydrate phase transitions, in industry and nature-except in the laboratory—cannot reach equilibrium. This has been extensively discussed in our previous studies [22-24]. We can obtain the degree of superheating needed for dissociation of hydrates to liquid water and guest molecule back to its original phase (this is not included in this study but in a subsequent work to this).

There are substantial deviations between various experimental data. Likewise, calculations based on both the Clapeyron and Clausius-Clapeyron also vary considerably. The proposed residual thermodynamic scheme is even very much numerically simpler than Anderson's Clapeyron scheme $[14,25,26]$ that goes through ice, and it is directly adaptable to gas mixtures. This study is a 
continuation of our previous work [26] in the Project, "Simultaneous production of energy from in-situ methane hydrate and long-termed offshore storage of $\mathrm{CO}_{2}$ ". However, this work focuses on application or implication of the enthalpies. This work also involves use of more extensive literature, and we also make available data of enthalpies of hydrate phase transitions from our residual thermodynamic approach that other researchers can make comparison with. This approach will be applied to hydrate systems involving mixture of hydrate formers in our subsequent work.

\section{Theoretical Analysis}

Pure methane forms a structure denoted as structure I. In this structure, water molecules form two types of cavities. The smallest cavity consists of 20 water molecules and is suitable for surrounding molecules like for instance methane. A larger cavity consisting of 24 water molecules is large enough to larger molecules like for instance ethane.

The cavities are stabilized by the molecular volume of the "guest" that enters the cavity and weakens attractive forces which typically decay proportionally to the distance between water and methane to the inverse of power 6 . This is similar to the attractive part of the Lennard-Jones (12-6) potential, and also the Kihara potential, which contains an additional parameter which is intended to imitate effects of molecular elongation.

Van der Waal and Platteeuw [27] used a semi grand canonical ensemble to derive a Langmuir type adsorption theory in which water molecules are fixed and rigid while molecules that enter cavities (guest molecules) are open to exchange with surrounding phases. The final result of the derivation is expressed in terms of chemical potential of water in hydrate:

$$
\mu_{\mathrm{H}_{2} \mathrm{O}}^{\mathrm{H}}=\mu_{\mathrm{H}_{2} \mathrm{O}}^{0, \mathrm{H}}-\sum_{k=1,2} R T v_{k} \ln \left(1+\sum_{i} h_{i j}\right)
$$

$\mu_{\mathrm{H}_{2} \mathrm{O}}^{\mathrm{H}}$ is the chemical potential of water in hydrate, while $\mu_{\mathrm{H}_{2} \mathrm{O}}^{0, \mathrm{H}}$ is the chemical potential of water in an empty clathrate for the given structure in consideration. Historically, this value has not been calculated by theoretical methods but rather fitted to experimental data in the form of chemical potential of pure liquid water minus empty clathrate water chemical potential. See Sloan and Koh [28] for some examples of values. $T$ stands for temperature, and $P$ is pressure. $k$ is an index for cavity types and $j$ is an index for guest molecules in the various cavities. Number of cavities is $v$, with subscripts $k$ for large and small cavities respectively. For structure I, which is the main focus here, $v_{\text {øarge }}=3 / 24$ and $v_{\text {small }}=1 / 24$. For structure II the corresponding numbers are $v_{\text {oarge }}=1 / 17$ and $v_{\text {small }}=2 / 17$.

The canonical partition functions for the cavities, $h_{i j}$ that will be a result of the grand canonical derivation will generally be an exponential function of the chemical potential time Boltzmann integrals over interactions between guests and water (generally also with surrounding guest molecules [29]). In the classical formulation of van der Waal and Platteeuw [27] the result for a rigid lattice is:

$$
h_{k i}=f_{i}^{g a s}(T, P, \vec{x}) C_{k i}(T)=x_{i} \varnothing_{i}(T, P, \vec{x}) P C_{k i}(T)
$$

The Langmuir constant $C_{k i}(T)$ for a molecule $i$ in cavity $k$ and given below as Equation (3). In the simplest case of a monoatomic spherical guest molecules, the Langmuir constant is a simple integral over the Boltzmann factors of interaction energies between the guest molecule and surrounding waters.

$$
C_{k i}(T)=\frac{1}{K_{B} T} \iiint e^{\beta\left[\varphi_{i v}(x, y, z)\right]} d x d y d z
$$

For non-linear multi-atomic representations of guest molecules, the integration will involve rotational degrees of freedom. 
The most common guest/water interaction model in present versions hydrate equilibrium codes based of the reference method is based on a spherically smeared out version of the Kihara potential for interactions between a water and a guest. The Kihara potential can be expressed as:

$$
\varnothing_{i j}\left(r_{i j}\right)=4 \varepsilon_{i j}\left[\left(\frac{\sigma_{i j}}{r_{i j}-a_{i j}}\right)^{12}-\left(\frac{\sigma_{i j}}{r_{i j}-a_{i j}}\right)^{6}\right]
$$

where $i$ and $j$ are molecular indices, while $r_{i j}-a_{i j}$ is the closest distance between the two molecules. $\sigma_{i j}$ is a molecular diameter, and $\varepsilon_{i j}$ is a well-depth. For $a_{i j}$ equal to zero, Equation (4) reduces to the Lennard-Jones (12-6) potential. A summation of approximate pairwise interactions in Equation (3) is possible and integration can be conducted efficiently using a Monte Carlo approach $[29,30]$. It is, however, more common to use an integrated smeared interaction version in which the average water/guest interaction are smeared out over the surface of a spherically smoothed cavity radius $R . Z$ is used as the number of waters represented in this spherical shell in Equation (4) below. $Z$ is therefore 20 for small cavity and 24 for large cavity. The details of this integration to reach at the spherically smoothed potential is far too extensive to include here. See reference [28] for more details and further references as well as examples of values for Equation (4). The final results for each specific cavity $k$ is:

$$
\begin{gathered}
\varphi_{i w}(r)=2 Z_{k} \varepsilon_{i w}\left[\frac{\sigma_{i w}^{12}}{R_{k}^{11} r}\left(\Delta^{10}+\frac{a_{i w}}{R_{k}} \Delta^{11}\right)-\frac{\sigma_{i w}^{6}}{R_{k}^{5} r}\left(\Delta^{4}+\frac{a_{i w}}{R_{k}} \Delta^{5}\right)\right] \\
\Delta^{N}=\frac{1}{N}\left[\left(1-\frac{r}{R_{k}}-\frac{a_{i w}}{R_{k}}\right)^{-N}-\left(1-\frac{r}{R_{k}}-\frac{a_{i w}}{R_{k}}\right)^{N}\right]
\end{gathered}
$$

The spherically symmetric integration version of Equation (3) can then be expressed as:

$$
C_{k i}(T)=\frac{4 \pi}{k_{B} T} \int_{0}^{\infty} e^{\beta\left[\varphi_{i v}(x, y, z)\right]} r^{2} d r
$$

Kvamme and Tanaka [31] also utilized a semi grand canonical ensemble and used molecular dynamics simulations to derive the same equation as Equation (1), but the meaning of chemical potential is now the physically average sampled chemical potential of water in empty clathrate based on a harmonic oscillator approach. These chemical potentials are therefore denoted as reference chemical potentials. Values for chemical potential of water in empty clathrates of structures I and II are plotted in Figure 1 below [30,31].

Parameters for linear fits of the various chemical potential in the plot is listed in Table 1 below.

$$
\frac{\mu_{H_{2} O}^{m}}{R T}=a_{0}^{m}+a_{1}^{m}\left(\frac{273.15}{T}\right)
$$

Table 1. Parameters for dimensionless chemical potential functions in Equation (8).

\begin{tabular}{ccc}
\hline Water Phase, $\boldsymbol{m}$ & $\boldsymbol{a}_{\mathbf{0}}$ & $\boldsymbol{a}_{\mathbf{1}}$ \\
\hline Empty structure I & -3.087 & -18.246 \\
Empty structure II & -3.188 & -18.186 \\
Ice $(T<273.15 \mathrm{~K})$ & -2.639 & -19.051 \\
Liquid water $(T>273.15 \mathrm{~K})$ & -5.610 & -16.080 \\
\hline
\end{tabular}




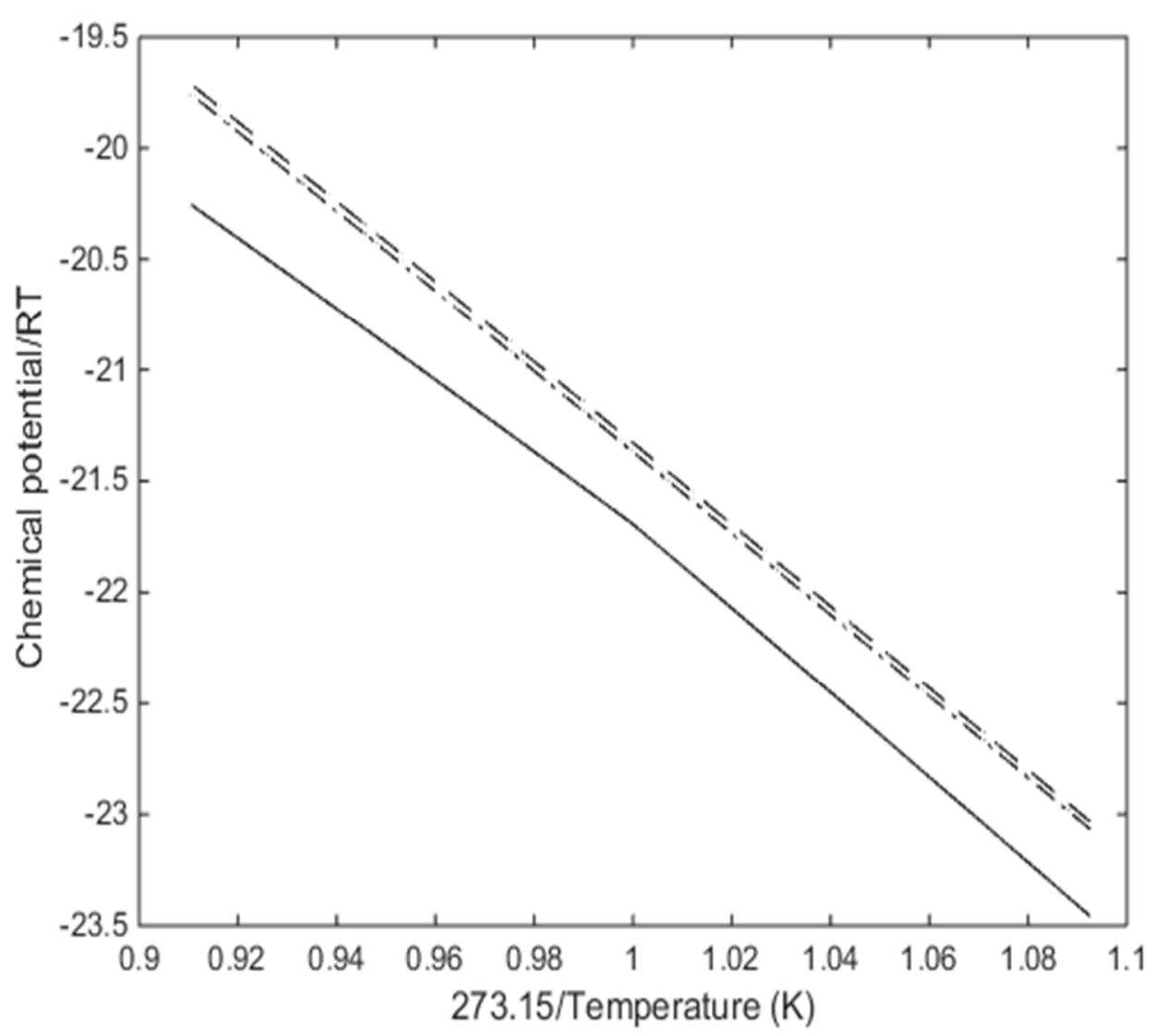

Figure 1. Dimensionless chemical potentials of water in empty clathrate of structure I (dashed-line), structure II (dash-dot line) and water as ice or liquid water (solid-line).

Similar for the evaluation of the canonical partition functions in Equation (1). These can also be evaluated for a rigid lattice in a similar fashion as Equation (2) but they can also be evaluated using a harmonic oscillator approach and be expressed as:

$$
h_{k i}=e^{\beta\left[\mu_{k i}-\Delta \mathrm{g}_{k i}\right]}
$$

where $\beta$ is equal to the inverse of the universal gas constant multiplied by temperature. $\Delta \mathrm{g}_{k i}$ stands for the effect on hydrate water for inclusion of a hydrate former (guest molecules) $i$ in the hydrate cavity $k$. In an equilibrium situation, the chemical potential of the hydrate forming molecules $i$ in the cavity (cage) $k$ is uniform with its (guest molecules $i$ ) chemical potential in the co-existing (original) phase it emanates from. Considering a non-equilibrium situation, adjustment of the chemical potential is done for distance from equilibrium through a Taylor expansion as will be discussed later. The free energies of inclusion, that is $\Delta g_{k i}$ have been reported in other works [22,32-34]. At thermodynamic equilibrium, $\mu_{k i}$ is the chemical potential of the hydrate forming guest molecule in its original phase (gas, liquid, or fluid) at the equilibrium pressure and temperature of the hydrate.

The composition of the hydrate is also trivially given by the derivation from the semi grand canonical ensemble and given by:

$$
\theta_{k i}=\frac{h_{k i}}{\sum_{j} h_{k i}}
$$

$\theta_{k i}$ is the filling fraction of component $i$ in cavity (cage) type $k$. Then:

$$
x_{i}^{H}=\frac{\theta_{\text {large }, i} v_{\text {large }}+\theta_{\text {small }, i} v_{\text {small }}}{1+\theta_{\text {large }, i} v_{\text {large }}+\theta_{\text {small }, i} v_{\text {small }}}
$$


where $v$ stands for the fraction of cavity in each water (i.e., per water) for the actual cavity (cage) type, as shown by the subscripts. The corresponding mole-fraction (concentration) of water is therefore:

$$
x_{\mathrm{H}_{2} \mathrm{O}}^{\mathrm{H}}=1-\sum_{i} x_{i}^{H}
$$

And the associated hydrate free energy is then:

$$
G^{(H)}=x_{H_{2} \mathrm{O}}^{H} \mu_{H_{2} \mathrm{O}}^{H}+\sum_{i} x_{i}^{H} \mu_{i}^{H}
$$

Outside of equilibrium the corresponding result for a Taylor expansion is given by:

$$
\begin{aligned}
& G_{\text {Non-equilibrium }}^{H}(T, P, \vec{x}) \\
& =H^{H, E q \cdot}\left(T^{E q \cdot}, P^{E q \cdot}, \vec{x}^{E q \cdot}\right)+\sum_{r} \frac{\partial G^{H}}{\partial x_{r}}{ }_{P, T, i \neq r}\left(x_{r}-x_{r}^{E q \cdot}\right) \\
& +\frac{\partial G^{H}}{\partial P}{ }_{T, x}\left(P-P^{E q .}\right)+{\frac{\partial G^{H}}{\partial T}}_{P, x}\left(T-T^{E q \cdot}\right)
\end{aligned}
$$

\section{Residual Thermodynamic Modelling of Hydrate Phase Transition}

With residual thermodynamics we are able to calculate real gas behaviour taking into account thermodynamic deviations from ideal gas behaviour [35]. A phase transition of hydrate (formation or dissociation) can be reversed along the pressure-temperature equilibrium curve of hydrate, just as it is used in the Clapeyron method for hydrate formation from a separate hydrate former phase (gas or liquid) and a free water phase. The change in the free energy for this hydrate phase change can be expressed as:

$$
\Delta G^{H}=\left[x_{H_{2} \mathrm{O}}^{H}\left(\mu_{H_{2} \mathrm{O}}^{H}\left(T, P, \vec{x}^{H}\right)-\mu_{H_{2} \mathrm{O}}^{\text {water }}(T, P, \vec{x})\right)+\sum_{j} x_{j}^{H}\left(\mu_{j}^{H}\left(T, P, \vec{x}^{H}\right)-\mu_{j}^{\text {gas }}\left(T, P, \vec{y}^{\text {gas }}\right)\right)\right]
$$

where superscript $H$ signifies hydrate phase in Equation (15). $T$ signifies temperature, and $P$ is pressure. $x$ signifies mole-fraction (hydrate or liquid phase), and $y$ denotes mole-fraction in hydrate former phase (gas or liquid). $j$ is an index for guest molecules or hydrate formers. Superscript water refers to water phase which is turned into hydrate. The water phase is usually liquid or ice, but in this study, we have considered liquid water only. And $\mu$ is chemical potential. The chemical potential of liquid water is estimated from the symmetric excess:

$$
\begin{gathered}
\mu_{\mathrm{H}_{2} \mathrm{O}}(T, P, \vec{x})=\mu_{\mathrm{H}_{2} \mathrm{O}, \mathrm{H}_{2} \mathrm{O}}^{\text {pure }}(T, P)+R \operatorname{Tln}\left[x_{\mathrm{H}_{2} \mathrm{O}} \gamma_{\mathrm{H}_{2} \mathrm{O}}(T, P, \vec{x})\right] \approx \mu_{\mathrm{H}_{2} \mathrm{O}}^{\text {pure, } \mathrm{H}_{2} \mathrm{O}}(T, P)+R T \ln \left[x_{\mathrm{H}_{2} \mathrm{O}}\right] \\
\lim \left(\gamma_{\mathrm{H}_{2} \mathrm{O}}\right)=1.0 \text { when } x_{\mathrm{H}_{2} \mathrm{O}} \text { approaches } 1
\end{gathered}
$$

where $\gamma$ represents activity coefficient, superscript $\mathrm{H}_{2} \mathrm{O}$ signifies water phase and subscript $\mathrm{H}_{2} \mathrm{O}$ is liquid water. In Equation (16) the approximation on the right-hand side (R.H.S) is not necessary. A theoretical model can be used for the activity coefficient or Gibbs-Duhem equation [36]. $\mathrm{CH}_{4}$ solubility in water is very low, thus, the R.H.S of Equation (16) will then be close to pure water chemical potential. From to residual thermodynamics, the hydrate former $j$ chemical potential is given as:

$$
\mu_{i}(T, P, \vec{y})=\mu_{i}^{\text {pure, ideal gas }}(T, P, \vec{y})+R T \ln \left[y_{i} \varnothing_{i}(T, P, \vec{y})\right]
$$

where $y_{i}$ denotes mole-fraction of component $i$ in the gas mixture. $\varnothing_{i}$ represents the fugacity coefficient for component $i$. Ideal gas chemical potential for pure component $i$ can be trivially computed for any model molecule by means of statistical mechanics from mass and intramolecular structure (bond 
lengths and bond angles). The ideal gas chemical potential as well as density and temperature are obtainable from the momentum space canonical partition function. The Soave-Redlich-Kwong equation of state (SRK EOS) [37] have been used to calculate the fugacity coefficient and the density required for the ideal gas free energy evaluations.

Enthalpy change is trivially connected to the associated change in free energy thermodynamically as:

$$
\frac{\partial\left[\frac{\Delta G^{\text {Total }}}{R T}\right]_{P, N}}{\partial T}=-\left[\frac{\Delta H^{\text {Total }}}{R T^{2}}\right]
$$

superscript Total is brought in to also include the penalty of pushing away the old phases to make way for the new hydrate phase during hydrate formation. The total free energy change is in essence Equation (16) in addition to the interface free energy, multiplied by the area of contact between water and the hydrate forming phase in the nucleation stage of hydrate formation, divided by the number of molecules in the given core size. Since the critical nuclei sizes are small [15], the entire particle can be seen or considered as covered with water because of capillary forces. When the hydrate core grows beyond the critical core size, the penalty reduces rapidly in comparison to the free energy benefits of going into hydrate, given by Equation (16).

$$
\frac{\partial\left[\frac{\mu_{\mathrm{H}_{2} \mathrm{O}}^{\mathrm{O}}}{R T}\right]_{P, \vec{N}}}{\partial T}=\frac{\partial\left[\frac{\mu_{\mathrm{H}_{2} \mathrm{O}}^{0, \mathrm{O}}}{R T}\right]_{P, \vec{N}}}{\partial T}-\left[\frac{\partial}{\partial T}\right]_{P, \vec{N}}\left[\sum_{k=1,2} v_{k} \ln \left(1+\sum_{i} h_{k i}\right)\right]
$$

The water (liquid) phase in Equation (16), and the chemical potential of the empty hydrate, which is the first term on R.H.S. of Equation (19), is trivially evaluated from [31]. Then, the second term is rearranged as given in Equation (20):

$$
\left[\frac{\partial}{\partial T}\right]_{P, \vec{N}}\left[\sum_{k=1,2} v_{k} \ln \left(1+\sum_{i} h_{k i}\right)\right]=\left[\sum_{k=1,2} v_{k} \frac{\sum_{i}\left[\frac{\partial h_{k i}}{\partial T}\right]_{P, \vec{N}}}{\left(1+\sum_{i} h_{k i}\right)}\right]
$$

Differentiation of cavity partition functions can be written as:

$$
\left[\frac{\partial h_{k i}}{\partial T}\right]_{P, \vec{N}}=h_{k i}\left[-\frac{1}{R T^{2}}\left(\mu_{k i}-\Delta \mathrm{g}_{k i}\right)+\frac{1}{R T}\left(\frac{\partial \mu_{k i}}{\partial T}-\frac{\partial \Delta \mathrm{g}_{k i}}{\partial T}\right)\right]
$$

The partial differentiation in the last term on R.H.S. is numerically computed from the polynomial fits of [31]:

$$
\begin{gathered}
\frac{\partial\left[\frac{\mu_{H_{2} \mathrm{O}}^{\mathrm{H}}}{R T}\right]_{P, \vec{N}}}{\partial T}=\frac{\partial\left[\frac{\mu_{H_{2} \mathrm{O}}^{0, \mathrm{H}}}{R T}\right]_{P, \vec{N}}}{\partial T}+\left[\sum_{k=1,2} v_{k} \frac{\sum_{i} h_{k i}\left[\frac{1}{R T^{2}}\left(\mu_{k i}-\Delta \mathrm{g}_{k i}\right)+\frac{1}{R T}\left(\frac{\partial \mu_{k i}}{\partial T}-\frac{\partial \Delta \mathrm{g}_{k i}}{\partial T}\right)\right]}{\left(1+\sum_{i} h_{k i}\right)}\right] \\
\mu_{\mathrm{H}_{2} \mathrm{O}}^{0, H}=-R T^{2} \frac{\partial\left[\frac{\mu_{H_{2} \mathrm{O}}^{0, H}}{R T}\right]_{P, \vec{N}}}{\partial T}+\left[\sum_{k=1,2} v_{k} \frac{\sum_{i} h_{k i}\left[\left(\mu_{k i}-\Delta \mathrm{g}_{k i}\right)+T\left(\frac{\partial \mu_{k i}}{\partial T}-\frac{\partial \Delta \mathrm{g}_{k i}}{\partial T}\right)\right]}{\left(1+\sum_{i} h_{k i}\right)}\right]
\end{gathered}
$$

the enthalpy of water (liquid) is yet more trivially estimated with the use of numerical differentiation of the polynomial fit of chemical potential as a function of temperature $T$ as Kvamme and Tanaka [31] specified.

If we consider equilibrium scenario, the chemical potential of a specific hydrate former (guest molecule) in the two types of cages have to be uniform and they have to also be uniform with the 
chemical potential of the same hydrate former in the original phase that it is taken or extracted from. Considering a heterogeneous hydrate formation, it means the chemical potential of the hydrate former phase, either gas or liquid. Nevertheless, outside of equilibrium which represent industrial situation and nature, the gradients in chemical potentials as function of pressure, temperature and concentrations (mole-fractions) need to reflect how the hydrate former behaves in the cage.

Enthalpies of different hydrate formers in the two cavity types can be computed utilizing Monte Carlo simulations along the lines described by Kvamme et al. (1993) [29] and Kvamme and Førrisdahl (1993) [30] by sampling interactions energies between water and guest molecule, and efficient volumes from the movements of the guest molecules:

$$
H_{k i}^{R}=U_{k i}^{R}+\left(z_{k i}-1\right) R T
$$

$U$ here stands for energy and superscript $R$ signifies residual (interaction) contribution. $z_{k i}$ is compressibility factor for the hydrate forming guest $i$ in cavity $k$. The consistent ideal gas values for the same interaction models which have been used in computation of the residual values is trivial.

$$
z_{k i}=\frac{P V_{k i}}{k_{B} T}
$$

$k_{B}$ is Boltzmann's constant and $V_{k i}$ is the excluded volume of a hydrate forming molecule of type $i$ in cavity of type $k$. This latter volume can be calculated from the sampled volume of centre of mass movements together with the excluded volume because of water/guest occupation.

The differentiation of chemical potential of a hydrate former molecule $i$ in cavity (cage) type $k$ with respect to temperature, $T$ as required in Equation (22) is the negative of partial molar entropy for the same hydrate former molecule and can be computed as follows:

$$
\left[\frac{\partial \mu_{k i}}{\partial T}\right]_{N, \vec{N}}=\frac{\mu_{k i}-H_{k i}}{T}
$$

And Equation (23) can then be reorganised into:

$$
\mu_{H_{2} O}^{0, H}=-R T^{2} \frac{\partial\left[\frac{\mu_{H_{2} O}^{0, H}}{R T}\right]_{P, N}}{\partial T}+\left[\sum_{k=1,2} v_{k} \frac{\sum_{i} h_{k i}\left[H_{k i}-\Delta g_{k i}+T \frac{\partial \Delta \mathrm{g}_{k i}}{\partial T}\right]}{\left(1+\sum_{i} h_{k i}\right)}\right]
$$

The residual enthalpies for guest molecule in a separate hydrate former (guest molecule) phase are trivially evaluated from:

$$
H_{k i}^{R}=-R T^{2} \sum_{i} y_{i}\left[\frac{\partial \ln \varnothing_{i}^{\mathrm{gas}}}{\partial T}\right]_{P, y_{j \neq i}}
$$

The same Soave-Redlich-Kwong [37] equation of state (SRK EOS) is applied for estimating fugacity coefficients for the chemical potentials.

\section{Results and Discussion}

\subsection{Hydrate Equilibrium Curves Using Residual Thermodynamics}

Hydrate equilibrium (P-T) curves calculated for methane and carbon dioxide hydrates using our scheme based on residual thermodynamic scheme approach are plotted with experimental (and some calculated) data in Figure 2a,b. For $\mathrm{CH}_{4}$ hydrate, we compared our estimates with different 11 data sets from literature [14,38-46], and our $\mathrm{CO}_{2}$ hydrate estimates are also compared with 11 different data sets $[13,25,38,42,47-52]$. The agreement is sufficiently good even though we did not do any empirical data fitting because it is not a priority. Our priority is to have the statistical mechanical 
model used [31] without adjustable parameters in all aspect, including the chemical potential of empty hydrate and that of water (ice and liquid). For $\mathrm{CO}_{2}$ (Figure $2 \mathrm{~b}$ ) at $283 \mathrm{~K}$, a jump can be observed. This has been explained in some of our previous studies [53,54]. The jump represents a point where the hydrate former undergoes a phase split (from gas phase to both liquid + gas), if we increase the P-T conditions along the equilibrium curve. It is caused by a change to a higher density because of part of the $\mathrm{CO}_{2}$ becoming liquid at this higher pressure. This point is called a "quadruple point"; hydrate + liquid water + liquid $\mathrm{CO}_{2}+\mathrm{CO}_{2}$ gas co-exist at this point. Several literature do not show this jump. Some smoothen the curve and some stop their evaluations at this point. However, Ohgaki et al. [52] show this jump and show that these high pressures are due to liquid phase of $\mathrm{CO}_{2}$. Our calculations took account of the presence of both liquid $\mathrm{CO}_{2}$ and $\mathrm{CO}_{2}$ gas as from this quadruple point, which is realistic. Ohgaki et al. [52] performed their evaluations for each of the separate phases (liquid and gas) of $\mathrm{CO}_{2}$. However, this is not the focus of this paper. The focus is on reviewing and revealing the wide differences in values calculated for enthalpy changes of hydrate phase transition (formation or dissociation) and the importance of enthalpies in $\mathrm{CH}_{4}-\mathrm{CO}_{2}$ swap.

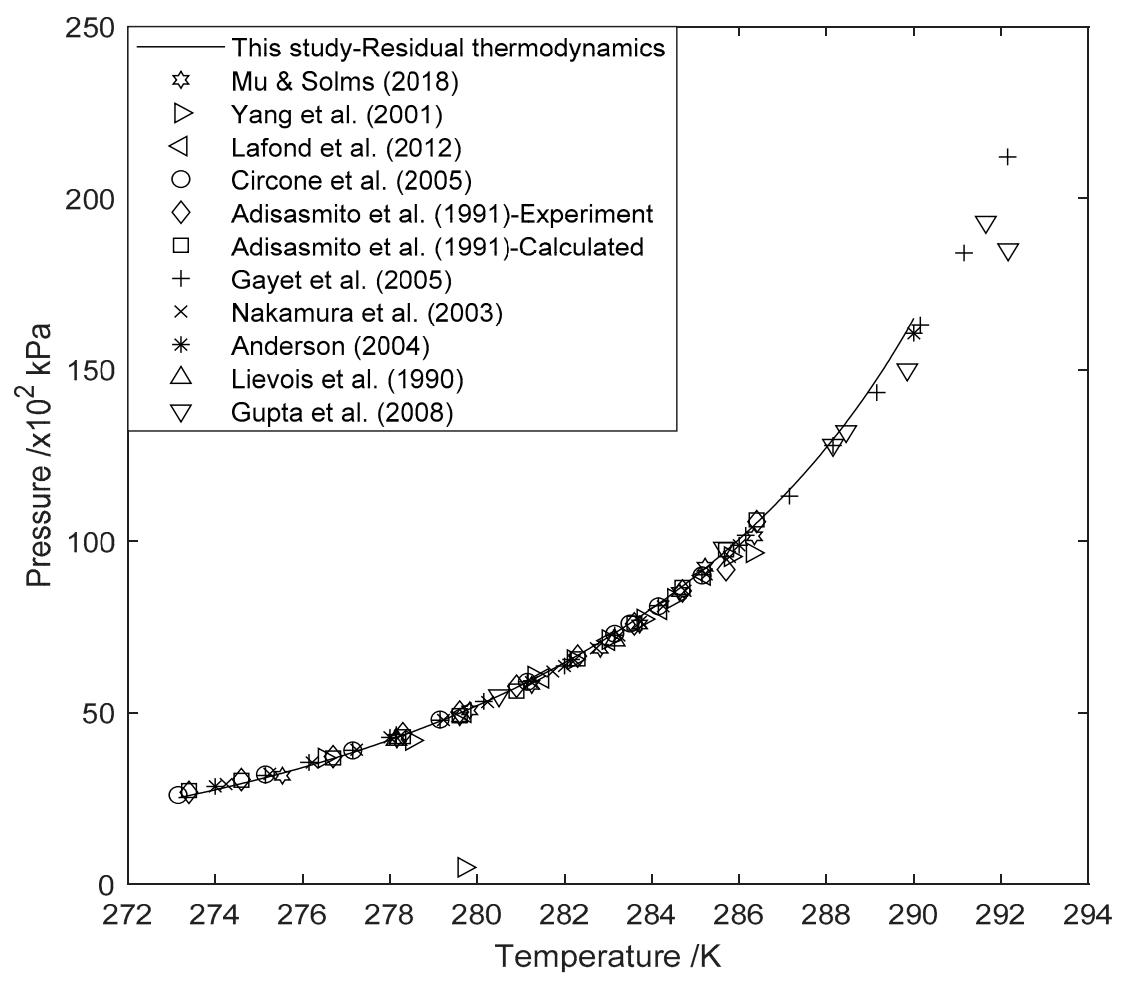

(a)

Figure 2. Cont. 


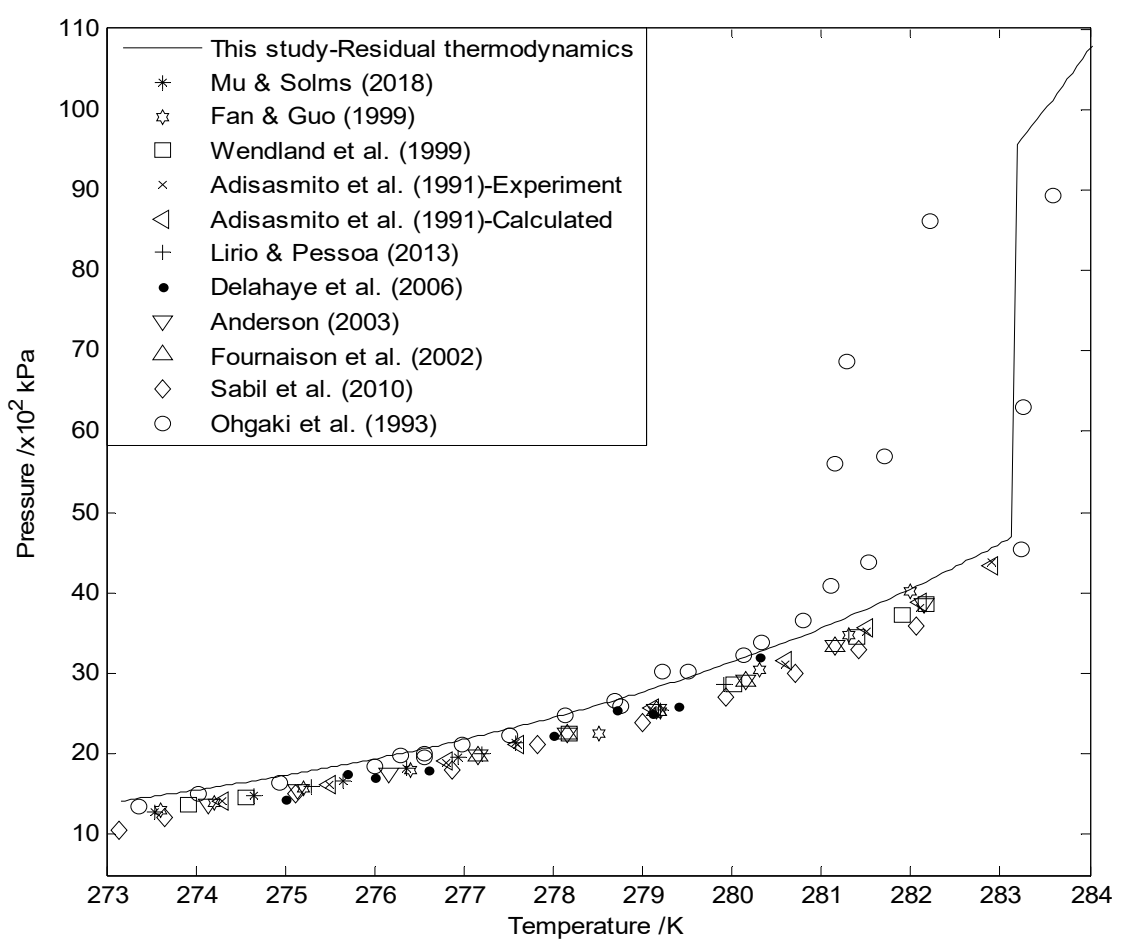

(b)

Figure 2. (a) Equilibrium (P, T) curve of methane (solid line) from residual thermodynamics compared with literature-experimental and calculated enthalpy data [14,38-46]; (b) Equilibrium $(\mathrm{P}, \mathrm{T})$ curve of carbon dioxide calculated from residual thermodynamics compared with literature-experimental and calculated enthalpy data $[13,25,38,42,47-52]$.

\subsection{Enthalpy Changes of Hydrate Formation or Dissociation: Residual Thermodynamics versus} Other Approaches

Enthalpy change of a hydrate phase transition, hydrate formation or dissociation is a very vital property of gas hydrate [13] as we have mentioned earlier. For example, to produce natural gas from the vast amount of in-situ methane hydrates dispersed in the world, information about the dissociation heat of these hydrates is very vital. In gas transport in form of hydrate, we also require this information about heat of formation and dissociation of the hydrate for effective and efficient gas recovery. Enthalpy change of hydrate formation or dissociation is normally obtained by direct measurement by means of experiment $[45,55,56]$, or indirectly by calculations based on thermodynamic models. The Clausius-Clapeyron [46,50,57] and Clapeyron [14,25,46] equations are generally used by many researchers. Some researchers use these equations with different modifications $[50,58]$. We have focused on only $\mathrm{CH}_{4}$ and $\mathrm{CO}_{2}$ hydrate guest molecules in this study because they are the relevant components in our project: simultaneous $\mathrm{CH}_{4}$ production from in-situ $\mathrm{CH}_{4}$ hydrate and long-term storage of $\mathrm{CO}_{2}$ as hydrate. We have also reported our calculations in hydrate dissociation (positive values). However, both formation and dissociation have the same values, negative values for hydrate formation since it is exothermic process and positive values for dissociation being an endothermic process.

In this section and the subsequent Sections 3.3 and 3.4, we are not using literature data to verify or validate our thermodynamic scheme. That has been done in Section 3.1. This is to show the picture of how the values obtained from the literature (even values from the same method) vary substantially. A look at several literature shows remarkable disagreement in reported values obtained for enthalpy changes of hydrate phase transition. Lirio and Pessoa [13] acknowledged this variation in literature values and their results. Thus, they [13] and some other literature have more confidence in their average values. 
Estimates using residual thermodynamics which we have proposed are plotted with several data sets (experimental and calculated data from the Clapeyron and Clausius-Clapeyron equations) from literature as can be seen in Figure $3 a, b$ and Figure 4a,b. We have plotted enthalpy changes of hydrate dissociation in $\mathrm{kJ} / \mathrm{mol}$ of guest molecule as a function of temperature for $\mathrm{CH}_{4}$ and $\mathrm{CO}_{2}$ in Figures $3 a$ and $4 \mathrm{a}$ respectively. While Figures $3 \mathrm{~b}$ and $4 \mathrm{~b}$ present enthalpy changes of hydrate dissociation in $\mathrm{kJ} / \mathrm{mol}$ of guest molecule as a function of pressure for $\mathrm{CH}_{4}$ and $\mathrm{CO}_{2}$ respectively. Figure $3 \mathrm{a}, \mathrm{b}$ also include our calculations using Clapeyron and Clausius-Clapeyron approaches. These figures represent what we have in literature now. They present the picture of varying values of enthalpy changes of hydrate formation and dissociation as mentioned above. For example, Gupta et al. [46] obtained different values for the enthalpy changes from experiment, Clapeyron and Clausius-Clapeyron approaches as presented in both Figure 3a,b. Our estimates using residual thermodynamics and the other two indirect methods also show great difference in values as can be seen in Figure 3a-Figure $4 \mathrm{~b}$. It is observed that Clausius-Clapeyron calculations give very high values, except when used with some modifications. The deviations are more in the case of $\mathrm{CO}_{2}$ as can be observed in Figure $4 \mathrm{a}, \mathrm{b}$. Nevertheless, for methane hydrate, the results of Nakamura et al. [44] are closed to our results, and also the experimental results of Gupta et al. [46] but only between 280 and $286 \mathrm{~K}$. A lot of literature reports a single value and sometimes it is the average of all the values calculated within a temperature range [13]. That is why we have only one value plotted for some studies in the figures. The single point value of Kang et al. [54] and Sloan and Fleyfel [58] are close to our results. We do not expect much agreement with our results based on the limitations of the other methods, especially, the simplicity of both the Clapeyron and Clausius-Clapeyron equations. Our calculations of enthalpy changes of hydrate dissociation and hydration (occupation) number for a temperature range of $273-290 \mathrm{~K}$ are presented in Table 2 with their pressures.

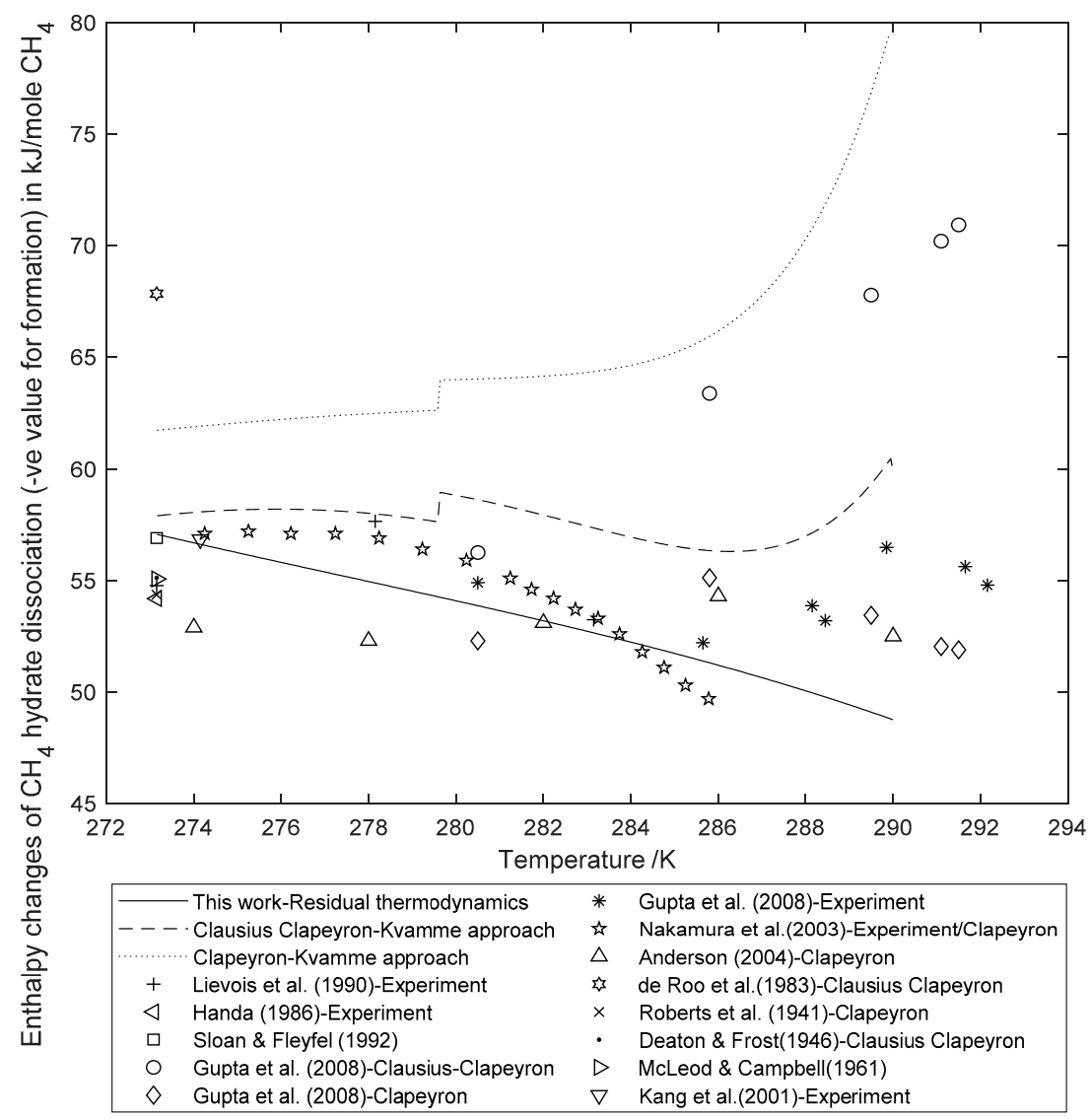

(a)

Figure 3. Cont. 


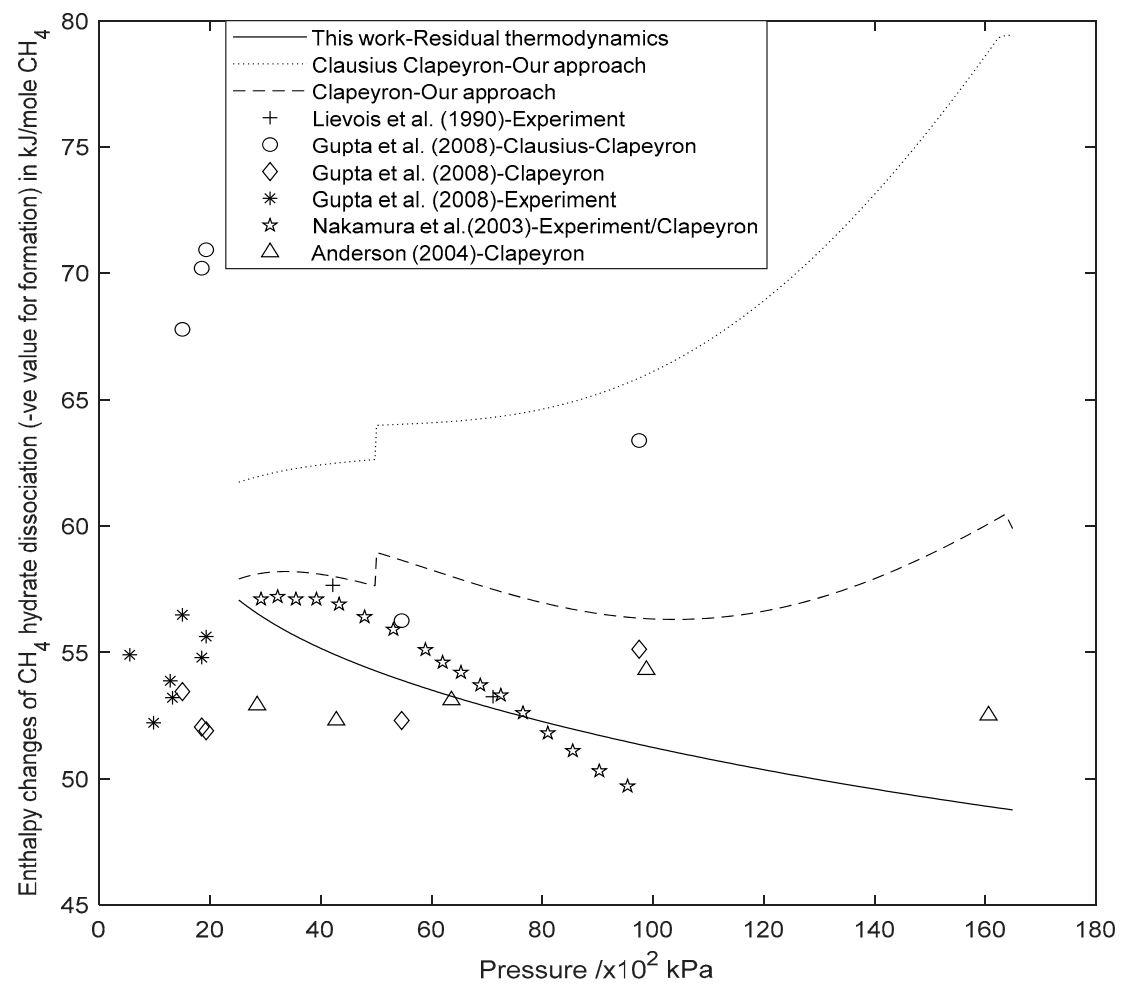

(b)

Figure 3. (a) Enthalpy changes of $\mathrm{CH}_{4}$ hydrate dissociation (negative values for formation) in $\mathrm{kJ} / \mathrm{mol}$ of $\mathrm{CH}_{4}$ as a function of temperature from residual thermodynamics compared with the literature [14,44-46,55-57,59-62]; (b) Enthalpy changes of $\mathrm{CH}_{4}$ hydrate dissociation (negative values for formation) in $\mathrm{kJ} / \mathrm{mol}$ of $\mathrm{CH}_{4}$ as a function of pressure from residual thermodynamics compared with the literature [14,44-46]. 


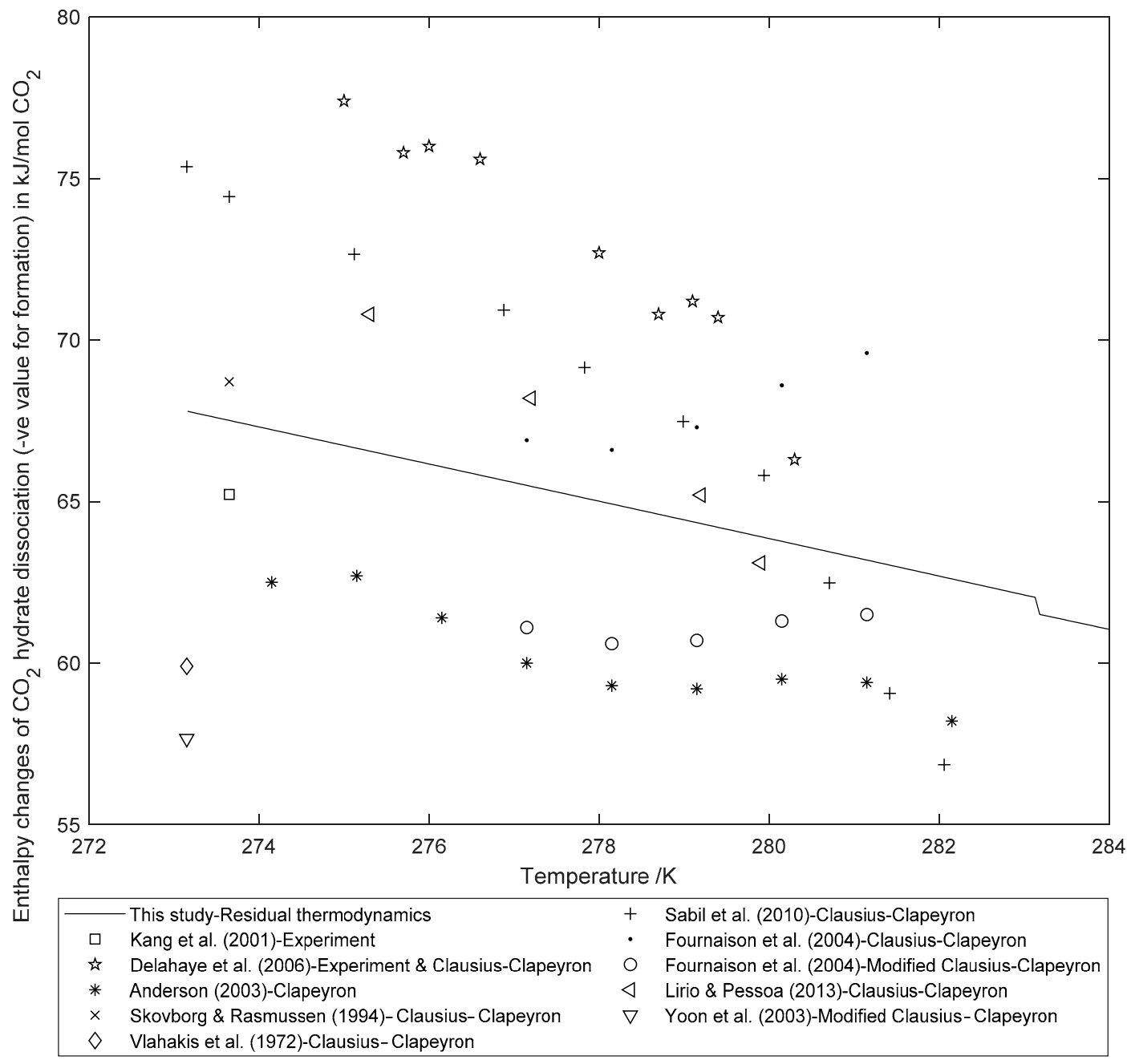

(a)

Figure 4. Cont. 


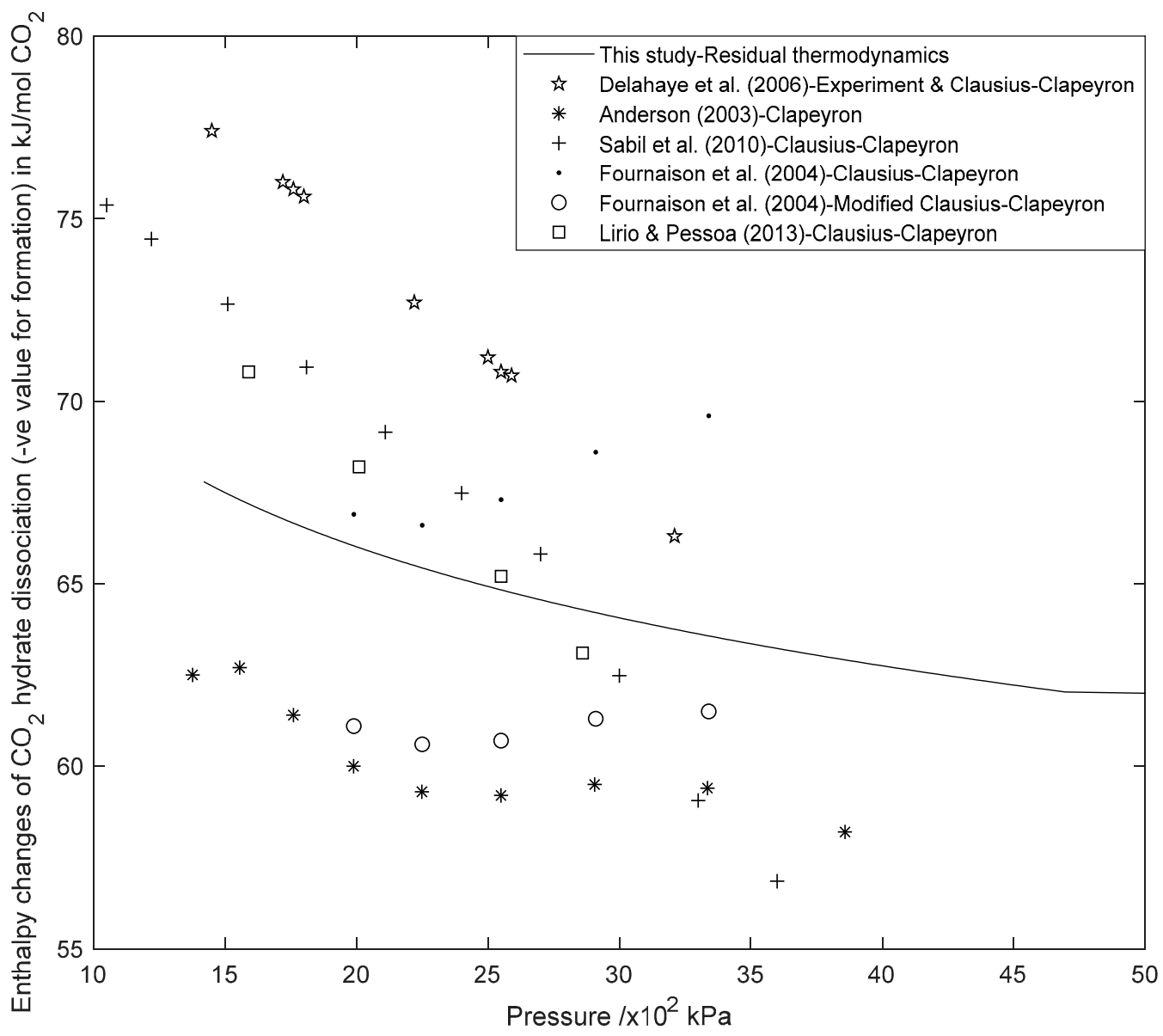

(b)

Figure 4. (a) Enthalpy changes of $\mathrm{CO}_{2}$ hydrate dissociation (negative values for formation) in $\mathrm{kJ} / \mathrm{mol}$ of $\mathrm{CO}_{2}$ as a function of temperature from residual thermodynamics compared with the literature $[13,25,49-51,55,58,63,64]$; (b) Enthalpy changes of $\mathrm{CO}_{2}$ hydrate dissociation (negative values for formation) in $\mathrm{kJ} / \mathrm{mol}$ of $\mathrm{CO}_{2}$ as a function of temperature from residual thermodynamics compared with the literature $[13,25,49-51]$. 
Table 2. Enthalpy changes of hydrate phase transition and hydration number of $\mathrm{CH}_{4}$ and $\mathrm{CO}_{2}$.

\begin{tabular}{|c|c|c|c|c|c|c|}
\hline \multirow{2}{*}{ Temperature } & \multicolumn{3}{|c|}{ Methane $\left(\mathrm{CH}_{4}\right)$} & \multicolumn{3}{|c|}{ Carbon Dioxide $\left(\mathrm{CO}_{2}\right)$} \\
\hline & $\begin{array}{c}\text { Pressure } \\
\qquad(\mathbf{k P a})\end{array}$ & $\begin{array}{l}\text { Hydration } \\
\text { Number (n) }\end{array}$ & $\begin{array}{c}\Delta H_{\text {dissociation }} \\
(\mathbf{k J} / \mathrm{mol} \\
\text { Guest) }\end{array}$ & $\begin{array}{c}\text { Pressure } \\
\text { (kPa) }\end{array}$ & $\begin{array}{l}\text { Hydration } \\
\text { Number (n) }\end{array}$ & $\begin{array}{c}\Delta H_{\text {dissociation }} \\
(\mathbf{k J} / \mathrm{mol} \\
\text { Guest) }\end{array}$ \\
\hline 273.16 & 25.19 & 6.46 & 57.07 & 14.19 & 7.26 & 67.79 \\
\hline 274.17 & 27.87 & 6.43 & 56.63 & 15.73 & 7.24 & 67.24 \\
\hline 275.13 & 31.01 & 6.41 & 56.19 & 17.59 & 7.22 & 66.67 \\
\hline 276.15 & 34.53 & 6.38 & 55.75 & 19.73 & 7.20 & 66.08 \\
\hline 277.16 & 38.45 & 6.37 & 55.31 & 22.21 & 7.18 & 65.50 \\
\hline 278.17 & 42.83 & 6.35 & 54.88 & 25.06 & 7.16 & 64.91 \\
\hline 279.13 & 47.43 & 6.34 & 54.47 & 28.17 & 7.14 & 64.36 \\
\hline 280.14 & 52.87 & 6.32 & 54.03 & 31.96 & 7.11 & 63.77 \\
\hline 281.16 & 58.97 & 6.31 & 53.57 & 36.34 & 7.09 & 63.18 \\
\hline 282.17 & 65.80 & 6.30 & 53.11 & 41.42 & 7.07 & 62.59 \\
\hline 283.13 & 73.03 & 6.30 & 52.66 & 46.95 & 7.05 & 62.03 \\
\hline 284.14 & 81.64 & 6.29 & 52.17 & 109.88 & 6.69 & 60.96 \\
\hline 285.15 & 91.41 & 6.28 & 51.65 & 128.38 & 6.67 & 60.40 \\
\hline 286.17 & 102.55 & 6.28 & 51.11 & 152.24 & 6.64 & 59.86 \\
\hline 287.13 & 114.65 & 6.27 & 50.57 & 183.38 & 6.62 & 59.39 \\
\hline 288.14 & 129.55 & 6.27 & 49.97 & 233.44 & 6.59 & 58.96 \\
\hline 289.16 & 147.28 & 6.26 & 49.33 & 313.22 & 6.57 & 58.68 \\
\hline 290.00 & 164.94 & 6.26 & 48.76 & 404.15 & 6.55 & 58.55 \\
\hline
\end{tabular}

\subsection{Hydration Number (n) Using Residual Thermodynamics versus Experimental Data}

Figure $5 \mathrm{a}, \mathrm{b}$ and Figure $6 \mathrm{a}, \mathrm{b}$ present the overview of the values of our estimates of the hydration number (n), which is the number of water per guest molecule, and recalculated back from the calculated mole-fractions of guests in hydrate. Literature values are also plotted. We have plotted values of $\mathrm{CH}_{4}$ and $\mathrm{CO}_{2}$ as a function of temperature (Figures $5 \mathrm{a}$ and $6 \mathrm{a}$ ) and as a function of pressure (Figures $5 \mathrm{~b}$ and $6 \mathrm{~b}$ ). These figures also present the overview values calculated by various literature and our consistent approach. Essentially, our aim here is not to validate our studies with literature values, having seen the limitations in the other methods. However, in the case of $\mathrm{CH}_{4}$ hydrate, the results of Galloway et al. [65] from their solid-solution theory at $283.15 \mathrm{~K}$ and $283.21 \mathrm{~K}$ agree with our results (Figure 5a,b). Kang et al. [55] value experimentally obtained at $273.65 \mathrm{~K}$ is also close (Figure 5a). In Figure 5b, that is from pressure perspective, the same theoretical results of Galloway [65] agree with our results. Uchida et al. [66] experimental results between $6000-8000 \mathrm{kPa}$ also have good agreement. 


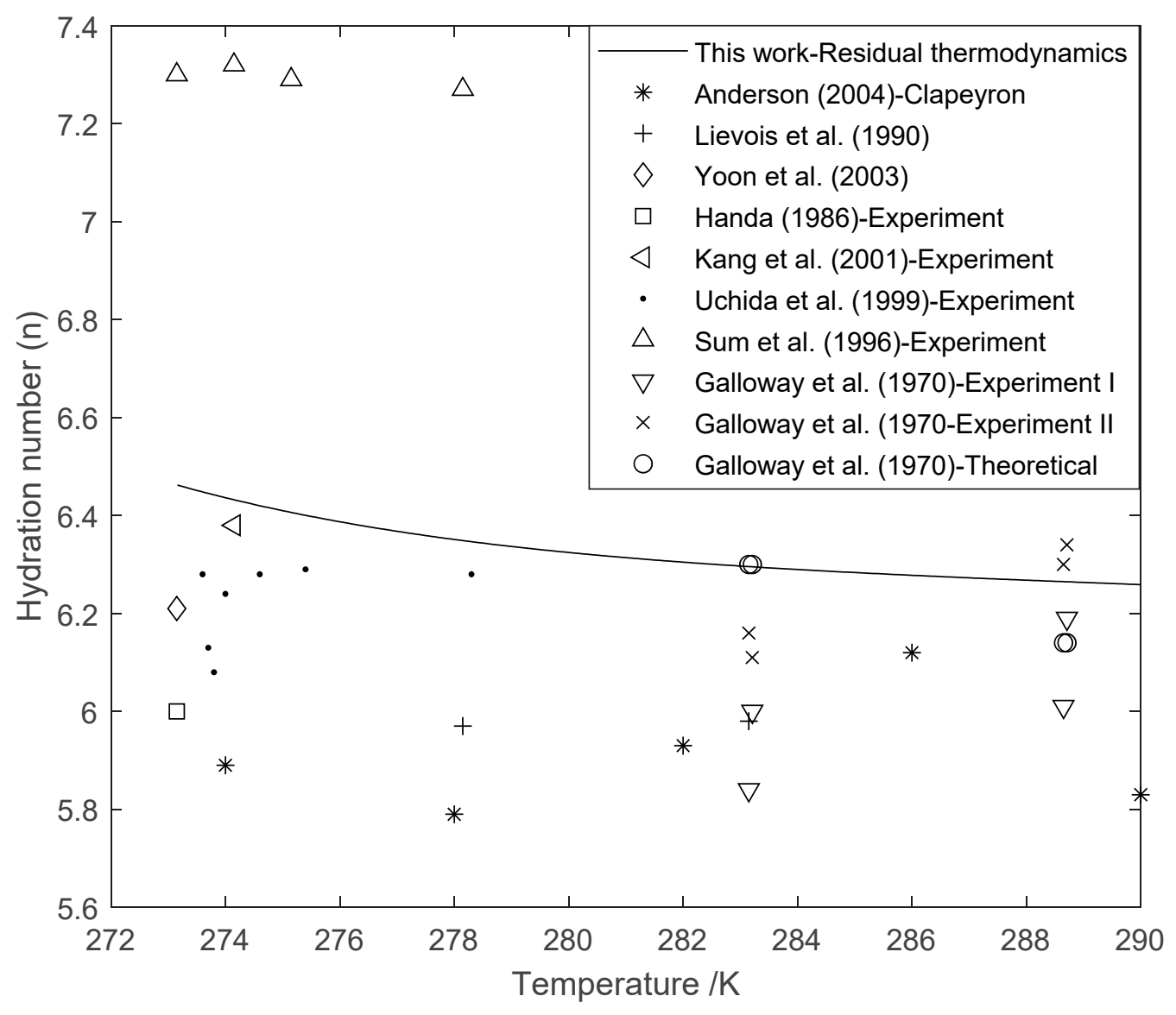

(a)

Figure 5. Cont. 


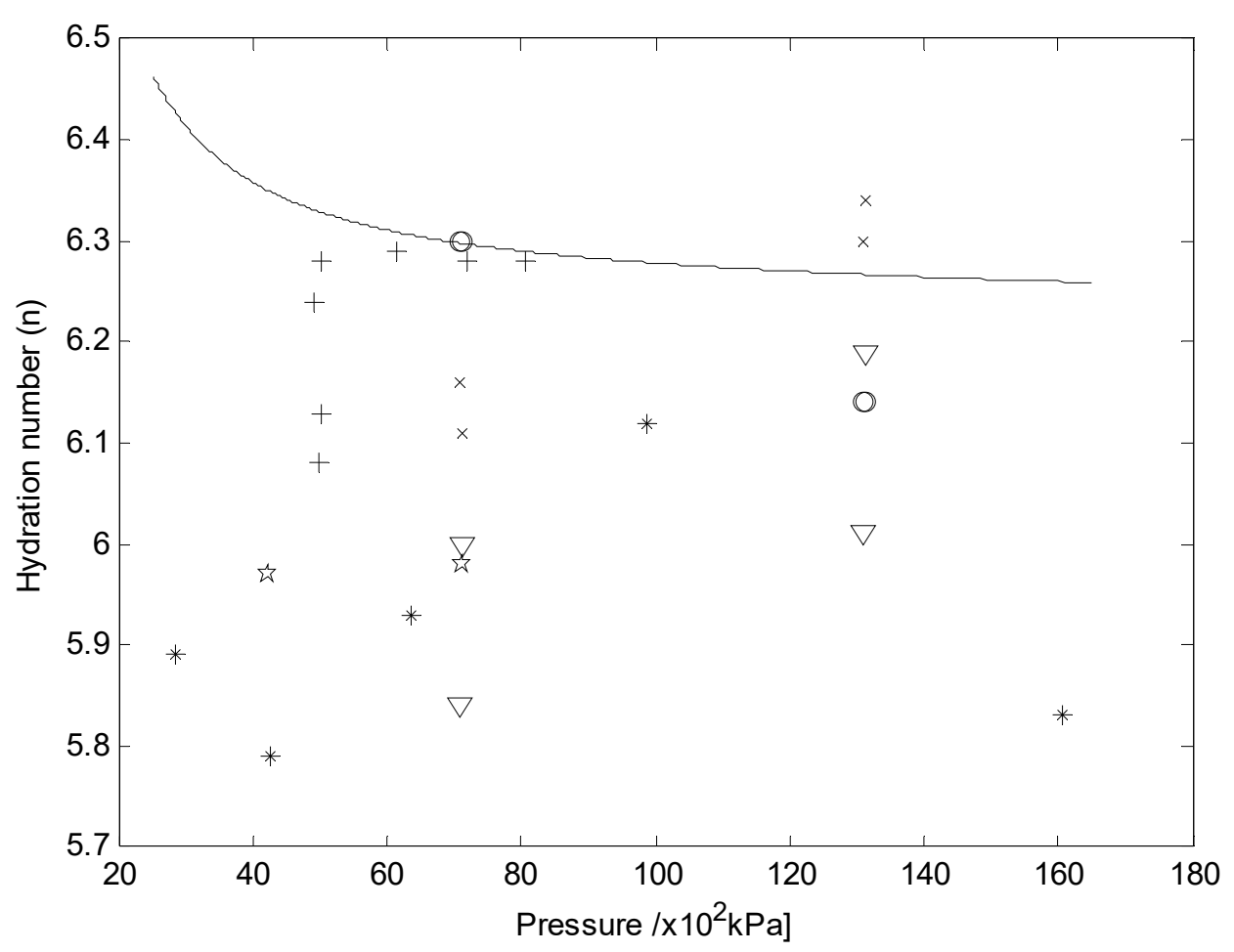

\begin{tabular}{|cl|}
\hline & This work-Residual thermodynamics \\
$*$ & Anderson (2004)-Clapeyron \\
+ & Lievois et al. (1990)-Experiment \\
+ & Uchida et al. (1999)-Experiment \\
$\nabla$ & Galloway et al. (1970)-Experiment I \\
$\times$ & Galloway et al. (1970-Experiment II \\
& Galloway et al. (1970)-Theoretical
\end{tabular}

(b)

Figure 5. (a) Hydration number of $\mathrm{CH}_{4}$ hydrate as a function of temperature from residual thermodynamics compared with the literature [14,45,55,56,58,65-67]; (b) Hydration number of $\mathrm{CH}_{4}$ hydrate as a function of pressure from residual thermodynamics compared with the literature $[14,45,65,66]$.

Both $\mathrm{CH}_{4}$ and $\mathrm{CO}_{2}$ are structure I hydrates. This structure has 46 molecules of water and two small and six large cavities. Since $\mathrm{CH}_{4}$ can occupy both the small and large cavities, if we assume full occupation which is not realistic, then we will have $2+6=8$ cavities that $\mathrm{CH}_{4}$ can occupy. This will give us a hydration number (n) of 46 water molecules divided by 8 cavities, which is 5.75 . Therefore, the realistic hydration number of methane hydrate should be greater than this value.

The hydration number of $\mathrm{CO}_{2}$ hydrate values obtained experimentally by Kang et al. [55], Bozzo et al. [68] and the value calculated by Vlahakis [64] from their Clausius-Clapeyron approach have good agreement with our results (Figure 6a). The results of Lirio and Pessoa. [13] along the hydrate equilibrium are not in agreement with our results. However, as mention earlier, they have more confidence in their average value and that is the value they compared with other literature. That is the value that is also in agreement with our results as can be seen in both Figure 6a,b. 


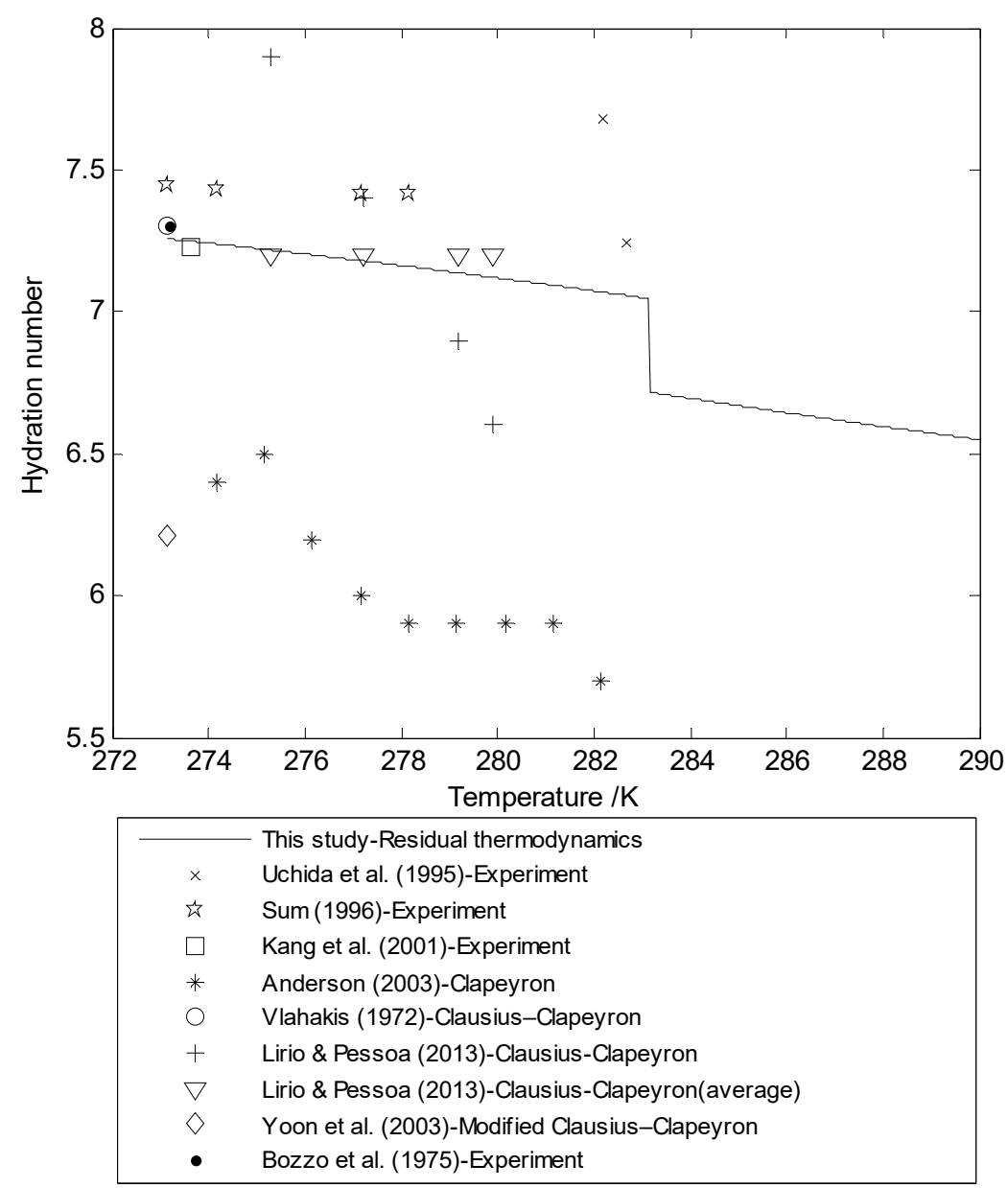

(a)

Figure 6. Cont. 

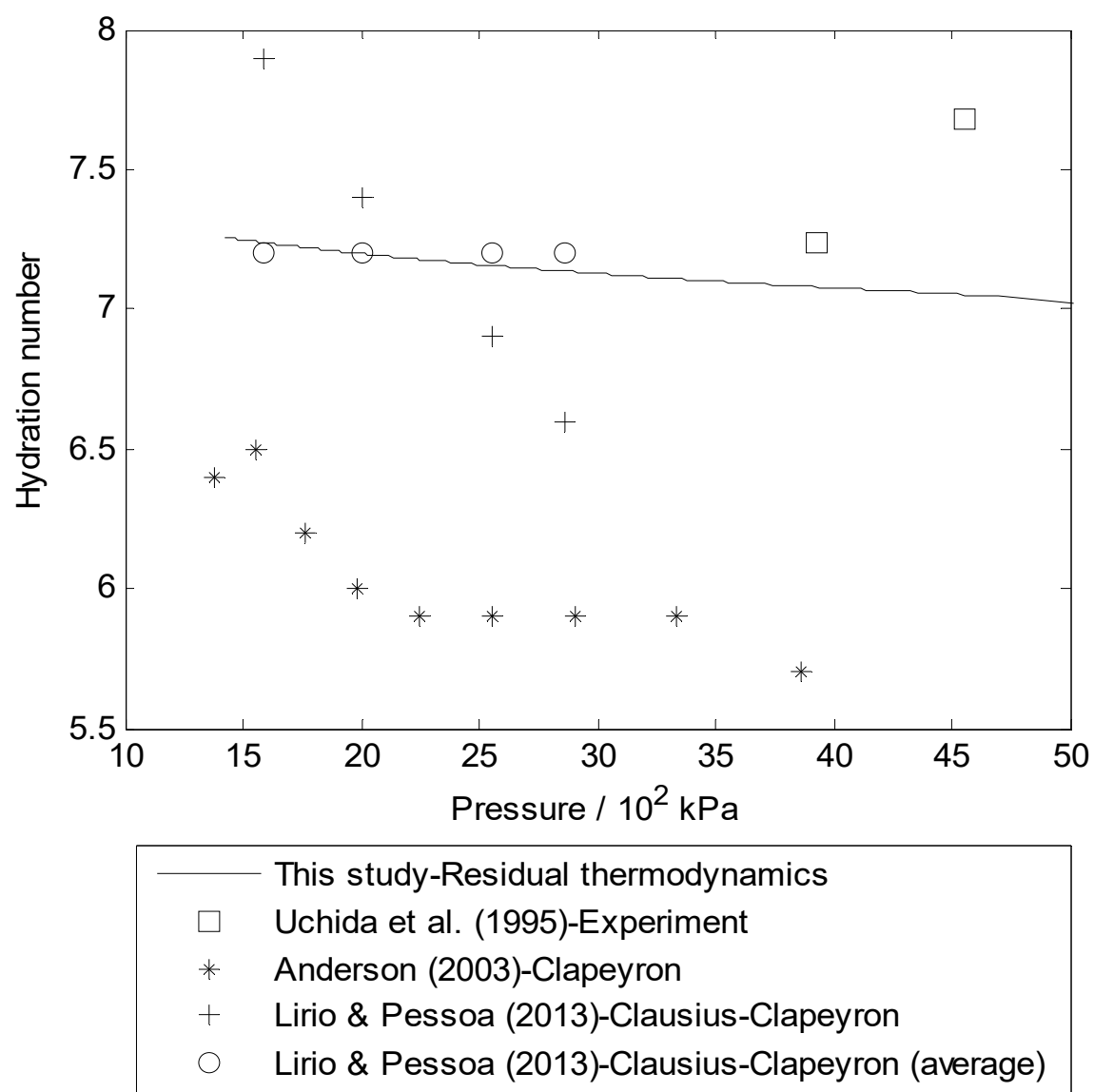

(b)

Figure 6. (a) Hydration number of $\mathrm{CO}_{2}$ hydrate as a function of temperature from residual thermodynamics compared with the literature $[13,25,55,58,64,67-69]$; (b) Hydration number of $\mathrm{CO}_{2}$ hydrate as a function of pressure from residual thermodynamics compared with the literature $[13,25,69]$.

\subsection{The Significance of Enthalpy Changes of Hydrate Formation or Dissociation in $\mathrm{CH}_{4}-\mathrm{CO}_{2}$ Swap}

Beside the problem gas hydrates can pose in industrial applications involving pipeline transport of gas $[23,24,53,70-73]$, the vast naturally occurring hydrates also offer potential possibility to provide a huge source of cleaner energy (compared to other fossil fuels) to the world, and a possibility of $\mathrm{CO}_{2}$ sink (long-term storage) [54]. Much attention has been given to the production of natural gas from the abundant in-situ methane hydrate spread across the world. Highly populated nations like China, Japan, and Indian who depend on huge import of fuel for energy have been investing a lot of money in research and tests towards realizing self-sufficiency in energy through exploration of these vast source of cleaner energy. Pressure reduction [74] below hydrate stability pressure is one major method that is being explored. This can only take care of the thermodynamic driving force. However, whatever technology that will be used to produce these vast energy resources will require supply of heat to ensure successful operation. The lessons learnt from the two tests already carried out offshore of Japan [75] few years ago agree with this. Among other challenges, they encountered a freezing down problem because of insufficient heat supply from the surroundings. One solution to this is thermal stimulation [76], that is, by supplying heat using either hot water or steam. While it is possible technologically, economically, it has been assessed to be too expensive. Therefore, a novel solution which is an environmentally friendly solution is injection of carbon dioxide $\left(\mathrm{CO}_{2}\right)$ into the reservoir of sin-situ $\mathrm{CH}_{4}$ hydrate deposits. This is the focus in this section. Lee et al. [77] and also Falenty et al. [78] had confirmed a solid-state $\mathrm{CO}_{2}-\mathrm{CH}_{4}$ swap process but in the ice region. The main aim in this section is to draw our attention to the significance of the role enthalpies of $\mathrm{CO}_{2}$ hydrate 
formation and enthalpies of $\mathrm{CH}_{4}$ hydrate formation can play in the swap process. Figure 7a and Figure $8 \mathrm{~b}$ present our estimates of enthalpy changes of hydrate formation and dissociation.

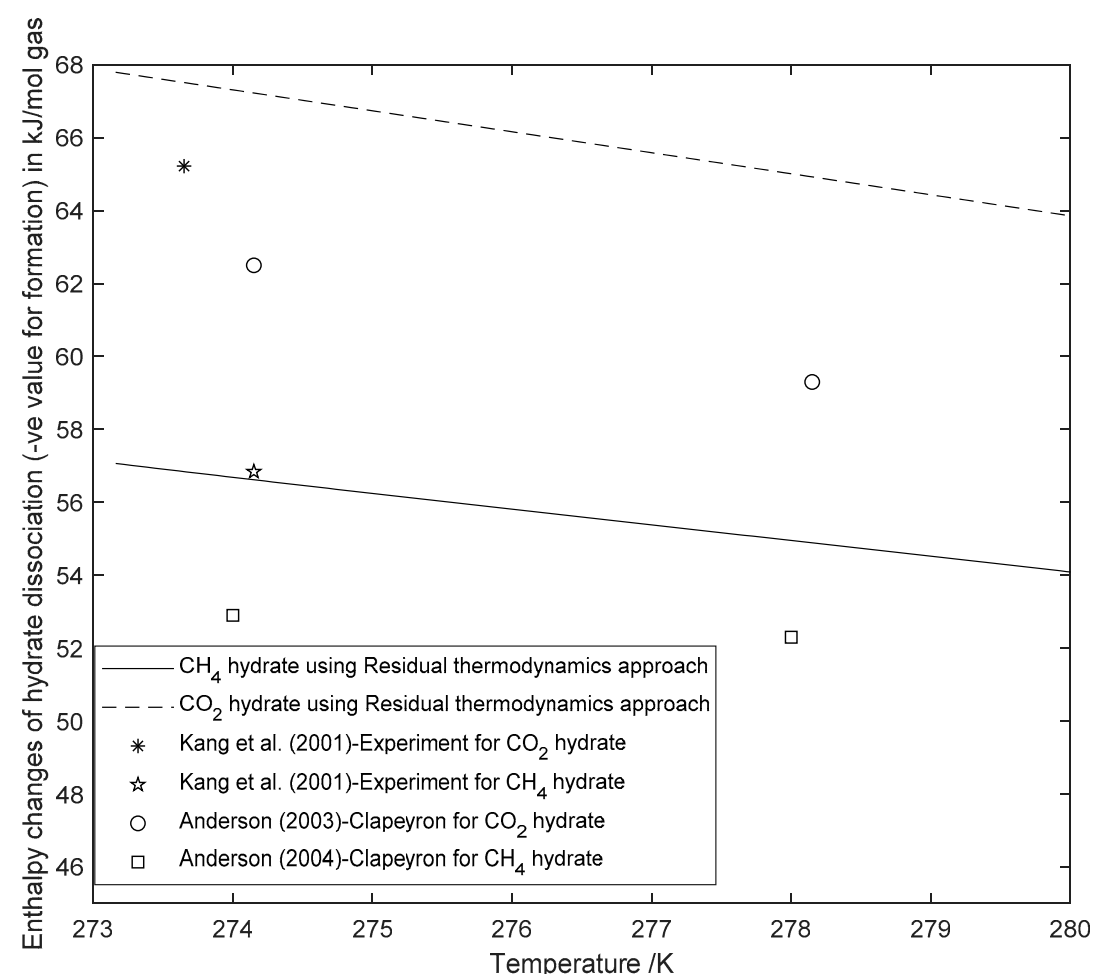

(a)

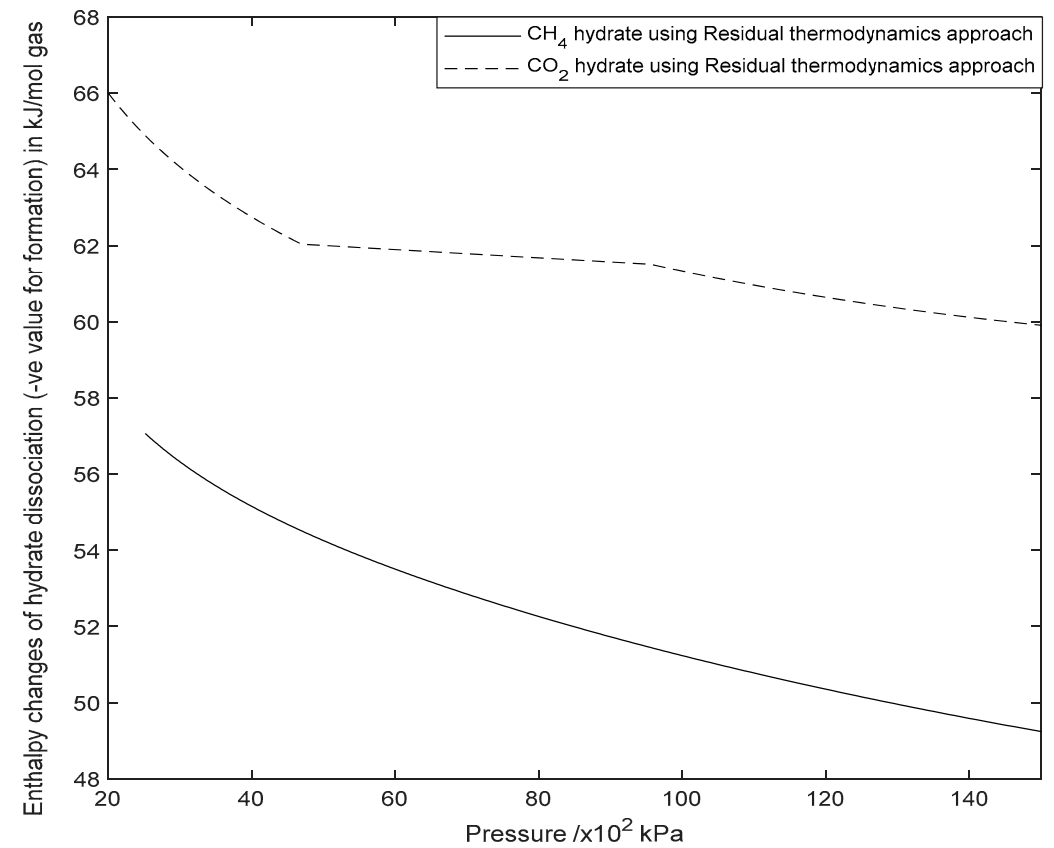

(b)

Figure 7. (a) Comparison of enthalpy changes of $\mathrm{CH}_{4}$ and $\mathrm{CO}_{2}$ hydrate dissociation (negative values for formation) as a function of temperature in $\mathrm{kJ} / \mathrm{mol}$ of guest molecule from residual thermodynamics compared with the literature $[14,25,55]$; (b) Comparison of enthalpy changes of $\mathrm{CH}_{4}$ and $\mathrm{CO}_{2}$ hydrate dissociation (negative values for formation) as a function of pressure in $\mathrm{kJ} / \mathrm{mol}$ of guest molecule from residual. 


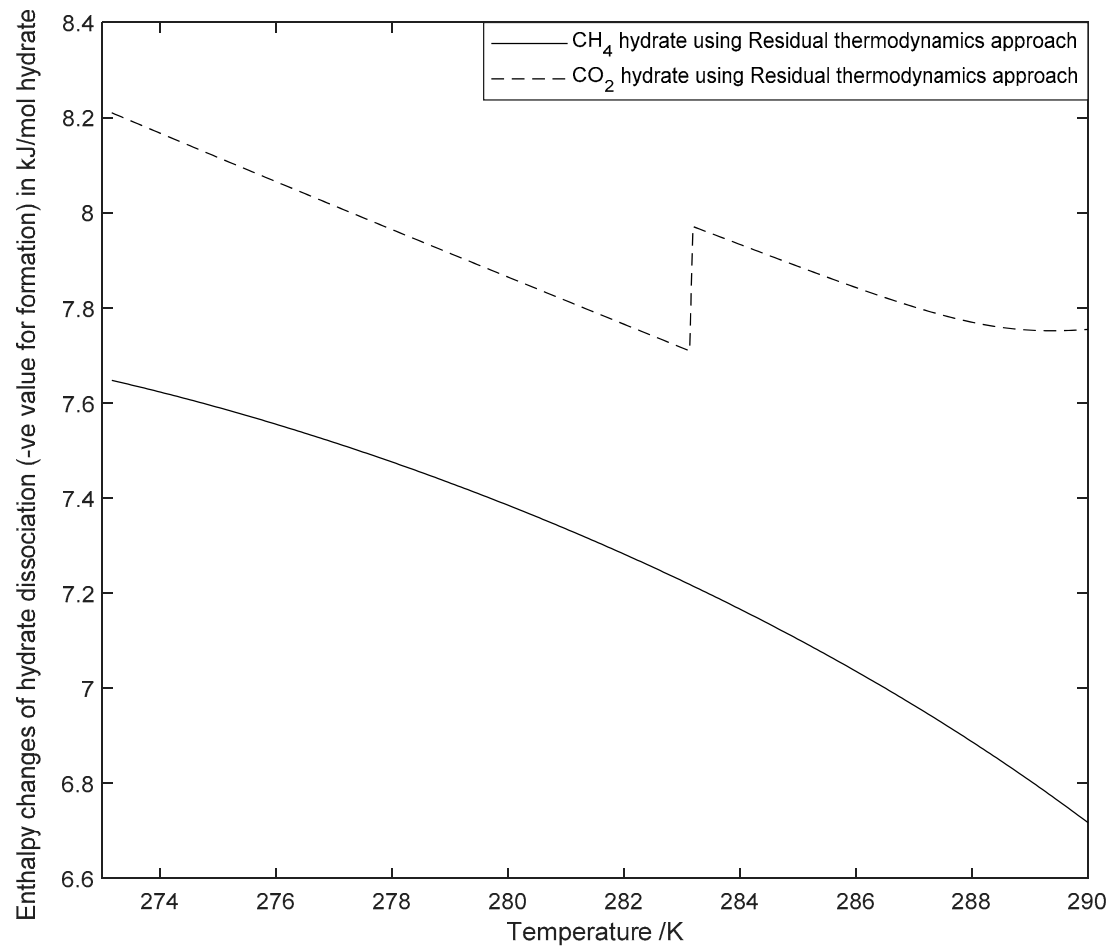

(a)

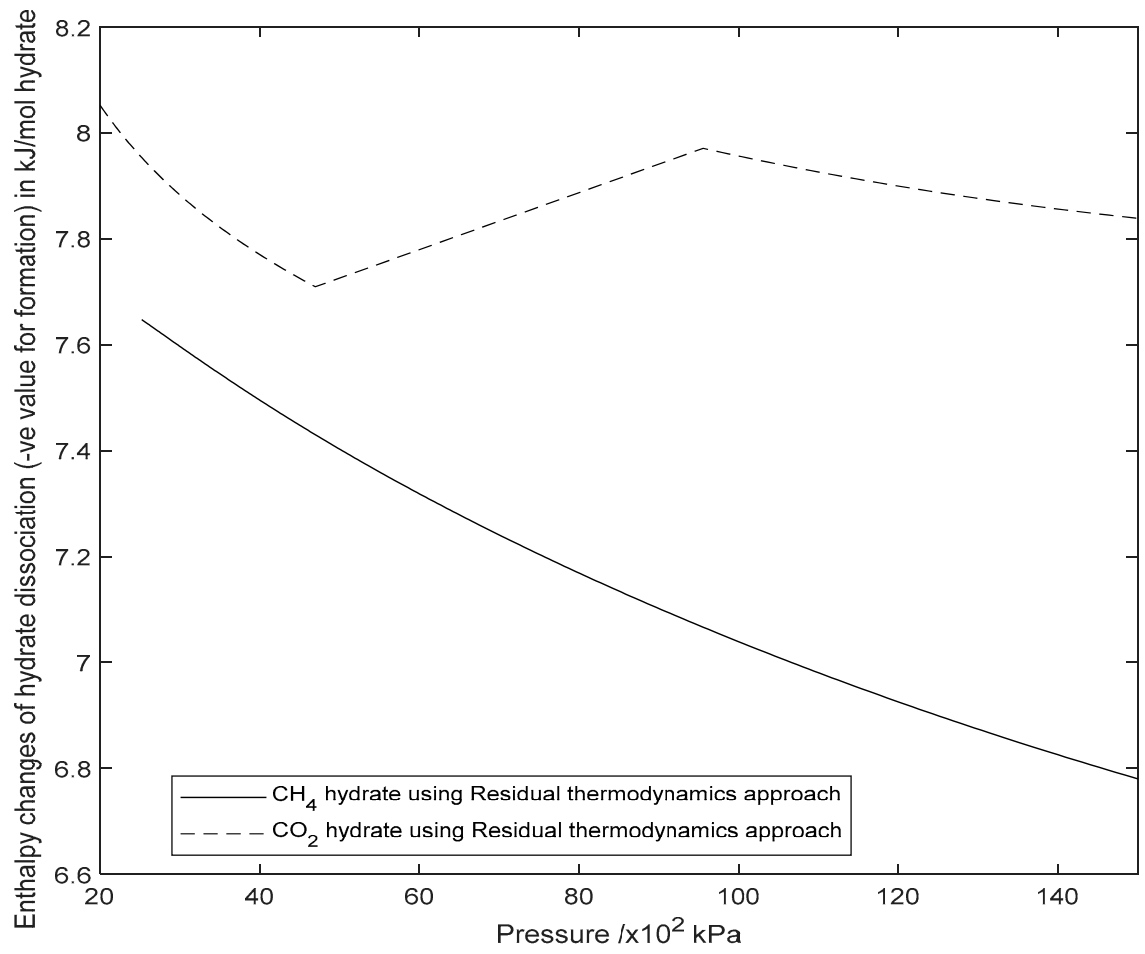

(b)

Figure 8. (a) Comparison of enthalpy changes of $\mathrm{CH}_{4}$ and $\mathrm{CO}_{2}$ hydrate dissociation (negative values for formation) as a function of temperature in $\mathrm{kJ} / \mathrm{mol}$ of hydrate from residual thermodynamics; (b) Comparison of enthalpy changes of $\mathrm{CH}_{4}$ and $\mathrm{CO}_{2}$ hydrate dissociation (negative values for formation) as a function of pressure in $\mathrm{kJ} / \mathrm{mol}$ of hydrate from residual thermodynamics. 
Hydrate formation is an exothermic process, and hydrate dissociation process is endothermic. It can be seen clearly in Figure $7 \mathrm{a}, \mathrm{b}$ and Figure $8 \mathrm{a}, \mathrm{b}$ that the enthalpy changes for $\mathrm{CO}_{2}$ hydrate phase transition are well over those for $\mathrm{CH}_{4}$ hydrate formation or dissociation. Considering a temperature range of $273-280 \mathrm{~K}$, the enthalpy changes we calculated from residual thermodynamics scheme for $\mathrm{CO}_{2}$ hydrate formation are approximately $10-11 \mathrm{~kJ} / \mathrm{mol}$ of guest molecule greater than the enthalpy changes of $\mathrm{CH}_{4}$ dissociation (see Figure 7a,b). Kang et al. [55] calculated this difference to be $8.4 \mathrm{~kJ} / \mathrm{mol}$ of guest molecule at $273.65 \mathrm{~K}$. Anderson [14,25] calculated approximately $10 \mathrm{~kJ} / \mathrm{mol}$ of guest molecule at $274 \mathrm{~K}$ and $7 \mathrm{~kJ} / \mathrm{mol}$ of guest molecule at $278 \mathrm{~K}$. These are significant differences (values). Basing the calculation on per mole of hydrate, we got about $0.5-0.6 \mathrm{~kJ} / \mathrm{mol}$ hydrate within a temperature range of $273-280 \mathrm{~K}$ as can be observed in Figure 8a,b. The implication is, when $\mathrm{CO}_{2}$ is injected into the in-situ methane hydrate reservoir, $\mathrm{CO}_{2}$ hydrate will be formed either directly through a solid-state process or from the available free water (including pore water). Since $\mathrm{CO}_{2}$ hydrate formation is an exothermic process, heat that is $10-11 \mathrm{~kJ} / \mathrm{mol}$ of guest molecule greater than the heat requirement for $\mathrm{CH}_{4}$ hydrate dissociation will be released. This heat is then available for further dissociation of $\mathrm{CH}_{4}$ hydrate to liquid water and $\mathrm{CH}_{4}$ gas. The $\mathrm{CH}_{4}$ will be released through buoyancy forces and the liquid water will be available for further $\mathrm{CO}_{2}$ hydrate formation and the process will go on. It is important to state here that this process is still under study and under development, and there are constraints which are also under investigation. $\mathrm{CO}_{2}$ hydrate formation from $\mathrm{CO}_{2}$ and pore water at the interface occurs very rapidly, which quickly forms a thin film of $\mathrm{CO}_{2}$ hydrate at the interface [15] thereby blocking the pore space to limit further supply of $\mathrm{CO}_{2}$. There have been suggestions of using nitrogen $\left(\mathrm{N}_{2}\right)$ in mixture with $\mathrm{CO}_{2}$ to reduce the driving force. This reduces the driving force so much and leads to a very slow $[33,71]$, ineffective and inefficient conversion of the in-situ $\mathrm{CH}_{4}$ hydrate to $\mathrm{CO}_{2}$ hydrate. Nevertheless, we recommend using surfactants instead of nitrogen, to reduce the hydrate nucleation and growth processes at the interface in order to enable an effective control of the simultaneous $\mathrm{CH}_{4}$ production and long-term $\mathrm{CO}_{2}$ storage in form of hydrate [79].

\section{Conclusions}

Enthalpy changes of hydrate phase transition is one of the most important properties of clathrate hydrate. However, the data in literature for enthalpy of hydrate formation and dissociation from experiment are lacking in vital information needed for proper understanding and interpretation. Indirect methods of obtaining this significant hydrate property based on the Clapeyron and Clausius-Clapeyron equations also have some limitations. The Clausius-Clapeyron approach for example involves oversimplifications that make results obtained from it to be inconsistent and unreliable. The approach can also not be used for very high-pressure systems. Therefore, we recommend a consistent thermodynamic scheme where every gas hydrate property such as hydrate pressure-temperature equilibrium curves, change in free energy (thermodynamic driving force in kinetic theories), and enthalpy changes involved in hydrate dissociation and formation are obtained based on residual thermodynamics approach. Calculations based on residual thermodynamics enable us to evaluate real gas behaviour with consideration of the thermodynamic deviations from ideal gas behaviour. We have given the overview of the estimates of enthalpy changes of hydrate phase transitions available in literature from experiments, Clapeyron and Clausius-Clapeyron approaches which shows remarkable disagreement in the various estimated values. Our calculations based on our proposed approach, and residual thermodynamics are plotted together. Overview of the available hydration number is also given in this work. The significance of these enthalpy changes of hydrate phase transitions to environmentally friendly energy production from in-situ methane hydrate and simultaneously storing carbon dioxide in form of gas hydrate is also highlighted in this study. Enthalpy changes of hydrate phase transition for $\mathrm{CO}_{2}$ are between 10-11 kJ/mol of guest molecule more than that of $\mathrm{CH}_{4}$ within a temperature range of $273-280 \mathrm{~K}$. Kang et al. calculated a difference of $8.4 \mathrm{~kJ} / \mathrm{mol}$ of guest molecule at $273.65 \mathrm{~K}$, and Anderson calculated it to be $10 \mathrm{~kJ} / \mathrm{mol}$ of guest molecule at $274 \mathrm{~K}$ and $7 \mathrm{~kJ} / \mathrm{mol}$ of guest molecule at $278 \mathrm{~K}$. And since heat is needed to be supplied from the surroundings during production 
of methane from in-situ methane hydrate, injection of $\mathrm{CO}_{2}$ into the reservoir of in-situ methane which will lead to $\mathrm{CO}_{2}$ hydrate formation will also provide more heat per guest molecule than the heat per guest molecule needed to dissociate methane hydrate.

Author Contributions: Conceptualization, formal analysis, investigation, writing most parts of the manuscript-original draft, final editing, S.A.A.; Conceptualization, methodology, software, writing part of the manuscript—original draft, and supervision, B.K.; Supervision and review, N.W.; Project administration, review, N.S.

Conflicts of Interest: The authors declare no conflict of interest.

\section{References}

1. Collett, T.S. Gas hydrates as a future energy resource. Geotimes 2004, 49, 24-27.

2. Makogon, Y.F.; Holditch, S.A.; Makogon, T.Y. Natural gas-hydrates-A potential energy source for the 21st Century. J. Pet. Sci. Eng. 2007, 56, 14-31. [CrossRef]

3. Fu, X.; Wang, J.; Tan, F.; Feng, X.; Wang, D.; He, J. Gas hydrate formation and accumulation potential in the Qiangtang Basin, northern Tibet, China. Energy Convers. Manage. 2013, 73, 186-194. [CrossRef]

4. Anderson, B.J.; Kurihara, M.; White, M.D.; Moridis, G.J.; Wilson, S.J.; Pooladi-Darvish, M.; Gaddipati, M.; Masuda, Y.; Collett, T.S.; Hunter, R.B.; et al. Regional long-term production modeling from a single well test, Mount Elbert gas hydrate stratigraphic test well, Alaska North slope. Mar. Petroleum. Geol. 2011, 28, 493-501. [CrossRef]

5. Zhu, Y.; Zhang, Y.; Wen, H.; Lu, Z.; Jia, Z.; Li, Y.; Li, Q.; Liu, C.; Wang, P.; Guo, X. Gas hydrates in the Qilian mountain permafrost, Qinghai, Northwest China. Acta. Geol. Sin. 2010, 84, 1-10. [CrossRef]

6. Boswell, R. Is gas hydrate energy within reach? Science 2009, 325, 957-958. [CrossRef]

7. Dunn, C.; Eshbaugh, M. Japan is the second largest net importer of fossil fuels in the world. US Energy Information Association. 7 November 2013. Available online: https://www.eia.gov/todayinenergy/detail. php?id=13711 (accessed on 7 December 2019).

8. Liu, C.; Ye, Y.; Meng, Q.; He, X.; Lu, H.; Zhang, J.; Liu, J.; Yang, S. The characteristics of gas hydrates recovered from Shenhu Area in the South China Sea. Mar. Geol. 2012, 307, 22-27. [CrossRef]

9. Lu, Z.; Zhu, Y.; Zhang, Y.; Wen, H.; Li, Y.; Liu, C. Gas hydrate occurrences in the Qilian Mountain permafrost, Qinghai province, China. Cold Reg. Sci. Technol. 2011, 66, 93-104. [CrossRef]

10. Collett, T.S. Energy resource potential of natural gas hydrates. AAPG bulletin 2002, 86, 1971-1992.

11. Klauda, J.B.; Sandler, S.I. Global distribution of methane hydrate in ocean sediment. Energ. Fuel 2005, 19, 459-470. [CrossRef]

12. Milkov, A.V. Global estimates of hydrate-bound gas in marine sediments: how much is really out there? Earth-Sci. Rev. 2004, 66, 183-197. [CrossRef]

13. Lirio, C.; Pessoa, F. Enthalpy of dissociation of simple and mixed carbon dioxide clathrate hydrate. Chem. Eng. Trans. 2013, 32, 557-582.

14. Anderson, G.K. Enthalpy of dissociation and hydration number of methane hydrate from the Clapeyron equation. J. Chem. Thermodyn. 2004, 36, 1119-1127. [CrossRef]

15. Kvamme, B.; Aromada, S.A.; Saeidi, N. Heterogeneous and homogeneous hydrate nucleation in $\mathrm{CO}_{2} /$ water systems. J. Cryst. Growth 2019, 522, 160-174. [CrossRef]

16. Kvamme, B.; Graue, A.; Aspenes, E.; Kuznetsova, T.; Gránásy, L.; Tóth, G.; Pusztai, T.; Tegze, G. Kinetics of solid hydrate formation by carbon dioxide: Phase field theory of hydrate nucleation and magnetic resonance imaging. Phys. Chem. Chem. Phys. 2004, 6, 2327-2334. [CrossRef]

17. Kvamme, B.; Qasim, M.; Baig, K.; Kivelä, P.H.; Bauman, J. Hydrate phase transition kinetics from Phase Field Theory with implicit hydrodynamics and heat transport. Int. J. Greenh. Gas Control 2014, 29, 263. [CrossRef]

18. Kivelä, P.H.; Baig, K.; Qasim, M.; Kvamme, B.R. Phase field theory modeling of methane fluxes from exposed natural gas hydrate reservoirs. AIP Conf. Proc. 2012, 1504, 351-363.

19. Svandal, A.; Kvamme, B.; Grànàsy, L.; Pusztai, T.; Buanes, T.; Hove, J. The phase-field theory applied to $\mathrm{CO}_{2}$ and $\mathrm{CH}_{4}$ hydrate. J. Cryst. Growth 2006, 287, 486-490. [CrossRef]

20. Tegze, G.; Pusztai, T.; Tóth, G.; Gránásy, L.; Svandal, A.; Buanes, T.; Kuznetsova, T.; Kvamme, B. Multiscale approach to $\mathrm{CO}_{2}$ hydrate formation in aqueous solution: Phase field theory and molecular dynamics. Nucleation and growth. J. Chem. Phys. 2006, 124, 234710. [CrossRef] 
21. Kvamme, B. Kinetics of Hydrate Formation from Nucleation Theory. Int. J. Off. Polar Eng. 2002, $12,256$.

22. Kvamme, B.; Kuznetsova, T.; Bauman, J.M.; Sjöblom, S.; Avinash Kulkarni, A. Hydrate Formation during Transport of Natural Gas Containing Water and Impurities. J. Chem. Eng. Data 2016, 61, 936-949. [CrossRef]

23. Aromada, S.A.; Kvamme, B. New approach for evaluating the risk of hydrate formation during transport of hydrocarbon hydrate formers of sI and sII. AIChE J. 2019, 65, 1097-1110. [CrossRef]

24. Kvamme, B.; Aromada, S.A. Risk of Hydrate Formation during the Processing and Transport of Troll Gas from the North Sea. J. Chem. Eng. Data 2017, 62, 2163-2177. [CrossRef]

25. Anderson, G.K. Enthalpy of dissociation and hydration number of carbon dioxide hydrate from the Clapeyron equation. J. Chem. Thermodyn. 2003, 35, 1171-1183. [CrossRef]

26. Kvamme, B.; Aromada, S.A.; Gjerstad, P.B. Consistent Enthalpies of the Hydrate Formation and Dissociation Using Residual Thermodynamics. J. Chem. Eng. Data 2019, 64, 3493-3504. [CrossRef]

27. van der Waals, J.H.; Platteeuw, J.C. Clathrate solutions. Advan. Chem. Phys. 1959, 2, 1-57.

28. Sloan, E.D., Jr.; Koh, C.A. Clathrate Hydrates of Natural Gases; CRC Press: Boca Raton, FL, USA, 2007.

29. Kvamme, B.; Lund, A.; Hertzberg, T. The influence of gas-gas interactions on the Langmuir constants for some natural gas hydrates. Fluid Phase Equilib. 1993, 90, 15-44. [CrossRef]

30. Kvamme, B.; Førrisdahl, O.K. Polar guest-molecules in natural gas hydrates. Effects of polarity and guest-guest-interactions on the Langmuir-constants. Fluid Phase Equilib 1993, 83, 427-435. [CrossRef]

31. Kvamme, B.; Tanaka, H. Thermodynamic stability of hydrates for ethane, ethylene, and carbon dioxide. J. Phys. Chem. 1995, 99, 7114-7119. [CrossRef]

32. Kvamme, B. Feasibility of simultaneous $\mathrm{CO}_{2}$ storage and $\mathrm{CH}_{4}$ production from natural gas hydrate using mixtures of $\mathrm{CO}_{2}$ and N2. Can. J. Chem. 2015, 93, 897-905. [CrossRef]

33. Kvamme, B. Thermodynamic Limitations of the $\mathrm{CO}_{2} / \mathrm{N} 2$ Mixture Injected into $\mathrm{CH}_{4} \mathrm{Hydrate}$ in the Ignik Sikumi Field Trial. J. Chem. Eng. Data 2016, 61, 1280-1295. [CrossRef]

34. Aromada, S.A. New Concept for Evaluating the Risk of Hydrate Formation during Processing and Transport of Hydrocarbons. Master's Thesis, The University of Bergen, Bergen, Norway, 2017.

35. Svandal, A. Modeling Hydrate Phase Transitions using Mean-Field Approaches. Ph.D. Thesis, University of Bergen, Bergen, Norway, 2006.

36. Gibbs, J.W. The Collected Works of J. Willard Gibbs, Thermodynamics; Yale university Press: New Haven, CT, USA, 1928; Volume 1, pp. 55-353.

37. Soave, G. Equilibrium constants from a modified Redlich-Kwong equation of state. Chem. Eng. Sci. 1972, 27, 1197-1203. [CrossRef]

38. Mu, L.; Solms, N.V. Hydrate thermal dissociation behavior and dissociation enthalpies in methane-carbon dioxide swapping process. J. Chem. Thermodyn. 2018, 117, 33-42. [CrossRef]

39. Yang, S.O.; Cho, S.H.; Lee, H.; Lee, C.S. Measurement and prediction of phase equilibria for water+ methane in hydrate forming conditions. Fluid Phase Equilib. 2001, 185, 53-63. [CrossRef]

40. Lafond, P.G.; Olcott, K.A.; Sloan, E.D.; Koh, C.A.; Sum, A.K. Measurements of methane hydrate equilibrium in systems inhibited with $\mathrm{NaCl}$ and methanol. J. Chem. Thermodyn. 2012, 48, 1-6. [CrossRef]

41. Circone, S.; Kirby, S.H.; Stern, L.A. Direct measurement of methane hydrate composition along the hydrate equilibrium boundary. J. Phys. Chem. B 2005, 109, 9468-9475. [CrossRef]

42. Adisasmito, S.; Frank, R.J., III; Sloan, E.D., Jr. Hydrates of carbon dioxide and methane mixtures. J. Chem. Eng. Data 1991, 36, 68-71. [CrossRef]

43. Gayet, P.; Dicharry, C.; Marion, G.; Graciaa, A.; Lachaise, J.; Nesterov, A. Experimental determination of methane hydrate dissociation curve up to $55 \mathrm{MPa}$ by using a small amount of surfactant as hydrate promoter. Chem. Eng. Sci. 2005, 60, 5751-5758. [CrossRef]

44. Nakamura, T.; Makino, T.; Sugahara, T.; Ohgaki, K. Stability boundaries of gas hydrates helped by methane-Structure-H hydrates of methylcyclohexane and cis-1, 2-dimethylcyclohexane. Chem. Eng. Sci. 2003, 58, 269-273. [CrossRef]

45. Lievois, J.S.; Perkins, R.; Martin, R.J.; Kobayashi, R. Development of an automated, high pressure heat flux calorimeter and its application to measure the heat of dissociation and hydrate numbers of methane hydrate. Fluid Phase Equilib. 1990, 59, 73-97. [CrossRef]

46. Gupta, A.; Lachance, J.; Sloan, E.D., Jr.; Koh, C.A. Measurements of methane hydrate heat of dissociation using high pressure differential scanning calorimetry. Chem. Eng. Sci. 2008, 63, 5848-5853. [CrossRef] 
47. Fan, S.-S.; Guo, T.-M. Hydrate formation of $\mathrm{CO}_{2}$-rich binary and quaternary gas mixtures in aqueous sodium chloride solutions. J. Chem. Eng. Data 1999, 44, 829-832. [CrossRef]

48. Wendland, M.; Hasse, H.; Maurer, G. Experimental pressure- temperature data on three-and four-phase equilibria of fluid, hydrate, and ice phases in the system carbon dioxide- water. J. Chem. Eng. Data 1999, 44, 901-906. [CrossRef]

49. Delahaye, A.; Fournaison, L.; Marinhas, S.; Chatti, I.; Petitet, J.P.; Dalmazzone, D.; Fürst, W. Effect of THF on equilibrium pressure and dissociation enthalpy of $\mathrm{CO}_{2}$ hydrates applied to secondary refrigeration. Ind. Eng. Chem. Res. 2006, 45, 391-397. [CrossRef]

50. Fournaison, L.; Delahaye, A.; Chatti, I.; Petitet, J.P. $\mathrm{CO}_{2}$ hydrates in refrigeration processes. Ind. Eng. Chem. Res. 2004, 43, 6521-6526. [CrossRef]

51. Sabil, K.M.; Witkamp, G.-J.; Peters, C.J. Estimations of enthalpies of dissociation of simple and mixed carbon dioxide hydrates from phase equilibrium data. Fluid Phase Equilib. 2010, 290, 109-114. [CrossRef]

52. Ohgaki, K.; Makihara, Y.; Takano, K. Formation of $\mathrm{CO}_{2}$ hydrate in pure and sea waters. J. Chem. Eng. Jpn. 1993, 26, 558-564. [CrossRef]

53. Kvamme, B.; Aromada, S.A. Alternative Routes to Hydrate Formation during Processing and Transport of Natural Gas with a Significant Amount of $\mathrm{CO}_{2}$ : Sleipner Gas as a Case Study. J. Chem. Eng. Data 2018, 63, 832-844. [CrossRef]

54. Aromada, S.A.; Kvamme, B. Production of Methane from Hydrate and $\mathrm{CO}_{2}$ Zero-Emission Concept. In Proceedings of the 10th EUROSIM2019 Congress, Logroño (La Rioja), Spain, 1-5 July 2019.

55. Kang, S.-P.; Lee, H.; Ryu, B.-J. Enthalpies of dissociation of clathrate hydrates of carbon dioxide, nitrogen, (carbon dioxide+ nitrogen), and (carbon dioxide+ nitrogen+ tetrahydrofuran). J. Chem. Thermodyn. 2001, 33, 513-521. [CrossRef]

56. Handa, Y. Compositions, enthalpies of dissociation, and heat capacities in the range 85 to $270 \mathrm{~K}$ for clathrate hydrates of methane, ethane, and propane, and enthalpy of dissociation of isobutane hydrate, as determined by a heat-flow calorimeter. J. Chem. Thermodyn. 1986, 18, 915-921. [CrossRef]

57. Deaton, W.; Frost, E., Jr. Gas Hydrates and Their Relation to the Operation of Natural Gas Pipe-Lines; US Bur. Mines Monograph 8; U.S. Department of Energy Office of Scientific and Technical Information: Oak Ridge, TN, USA, 1946.

58. Yoon, J.H.; Yamamoto, Y.; Komai, T.; Haneda, H.; Kawamura, T. Rigorous approach to the prediction of the heat of dissociation of gas hydrates. Ind. Eng. Chem. Res. 2003, 42, 1111-1114. [CrossRef]

59. Sloan, E.; Fleyfel, F. Hydrate dissociation enthalpy and guest size. Fluid Phase Equilib. 1992, 76, $123-140$. [CrossRef]

60. De Roo, J.L.; Peters, C.J.; Lichtenthaler, R.N.; Diepen, G.A.M. Occurrence of methane hydrate in saturated and unsaturated solutions of sodium chloride and water in dependence of temperature and pressure. AIChE J. 1983, 29, 651-657. [CrossRef]

61. Roberts, O.L.; Brownscombe, E.R.; Howe, L.S.; Ramser, H. Phase diagrams of methane and ethane hydrates. Petr. Eng. 1941, 12, 56.

62. McLeod, H.O.; Campbell, J.M. Natural gas hydrates at pressures to 10,000 psia. J. Pet. Technol. 1961, $222,590$. [CrossRef]

63. Skovborg, P.; Rasmussen, P. Comments on: Hydrate dissociation enthalpy and guest size. Fluid Phase Equilib. 1994, 96, 223-231. [CrossRef]

64. Vlahakis, J. The Growth Rate of Ice Crystals: The Properties of Carbon Dioxide Hydrate; A Review of Properties of 51 Gas Hydrates; Washington U.S. Dept. of the Interior: Syracuse University, NY, USA, 1972; Volume 830, p. 14.

65. Galloway, T.J.; Ruska, W.; Chappelear, P.S.; Kobayashi, R. Experimental measurement of hydrate numbers for methane and ethane and comparison with theoretical values. Ind. Eng. Chem. Fundam. 1970, 9, 237-243. [CrossRef]

66. Uchida, T.; Hirano, T.; Ebinuma, T.; Narita, H.; Gohara, K.; Mae, S.; Matoto, R. Raman spectroscopic determination of hydration number of methane hydrates. AIChE J. 1999, 45, 2641-2645. [CrossRef]

67. Sum, A.K. Measurements of clathrate hydrates properties via Raman spectroscopy. In Proceedings of the 2nd International Conference on Natural Gas Hydrates, Toulouse, France, 2-6 June 1996; pp. 51-58.

68. Bozzo, A.T.; Hsiao-Sheng, C.; Kass, J.R.; Barduhn, A.J. The properties of the hydrates of chlorine and carbon dioxide. Desalination 1975, 16, 303-320. [CrossRef] 
69. Uchida, T.; Takagi, A.; Kawabata, J.; Mae, S.; Hondoh, T. Raman spectroscopic analyses of the growth process of $\mathrm{CO}_{2}$ hydrates. Energy Convers. Manag. 1995, 36, 547-550. [CrossRef]

70. Hammerschmidt, E. Formation of gas hydrates in natural gas transmission lines. Ind. Eng. Chem. 1934, 26, 851-855. [CrossRef]

71. Kvamme, B.; Aromada, S.A.; Kuznetsova, T.; Gjerstad, P.B.; Canonge, P.C.; Zarifi, M. Maximum tolerance for water content at various stages of a natuna production. Heat Mass Transf. 2019, 55, 1059-1079. [CrossRef]

72. Aromada, S.A.; Kvamme, B. Impacts of $\mathrm{CO}_{2}$ and $\mathrm{H} 2 \mathrm{~S}$ on the risk of hydrate formation during pipeline transport of natural gas. Front. Chem. Sci. Eng. 2019, 13, 616-627. [CrossRef]

73. Aromada, S.A.; Kvamme, B. Simulation of Hydrate Plug Prevention in Natural Gas Pipeline from Bohai Bay to Onshore Facilities in China. In Proceedings of the 10th EUROSIM2019 Congress, Logroño (La Rioja), Spain, 1-5 July 2019.

74. Sloan, E.D. Fundamental principles and applications of natural gas hydrates. Nature 2003, 426, 353. [CrossRef] [PubMed]

75. Kvamme, B. Environmentally Friendly Production of Methane from Natural Gas Hydrate Using Carbon Dioxide. Sustainability 2019, 11, 1964. [CrossRef]

76. Ohgaki, K.; Takano, K.; Sangawa, H.; Matsubara, T.; Nakano, S. Methane Exploitation by Carbon Dioxide from Gas Hydrates-Phase Equilibria for $\mathrm{CO}_{2}-\mathrm{CH}_{4}$ Mixed Hydrate System. J. Chem. Eng. Jpn. 1996, 29, 478-483. [CrossRef]

77. Lee, H.; Seo, Y.; Seo, Y.T.; Moudrakovski, I.L.; Ripmeester, J.A. Recovering methane from solid methane hydrate with carbon dioxide. Angew. Chem. Int. Ed. 2003, 42, 5048-5051. [CrossRef]

78. Falenty, A.; Salamatin, A.; Kuhs, W. Kinetics of $\mathrm{CO}_{2}$-hydrate formation from ice powders: Data summary and modeling extended to low temperatures. J. Phys. Chem. C 2013, 117, 8443-8457. [CrossRef]

79. Buanes, T.; Kvamme, B.; Svandal, A. Computer simulation of $\mathrm{CO}_{2}$ hydrate growth. J. Cryst. Growth 2006, 287, 491-494. [CrossRef]

(C) 2019 by the authors. Licensee MDPI, Basel, Switzerland. This article is an open access article distributed under the terms and conditions of the Creative Commons Attribution (CC BY) license (http://creativecommons.org/licenses/by/4.0/). 